\title{
The burden, epidemiology, costs and treatment for Duchenne muscular dystrophy: an evidence review
}

\author{
S. Ryder ${ }^{1 *}$ D, R. M. Leadley ${ }^{1}$, N. Armstrong ${ }^{1}$, M. Westwood', S. de Kock', T. Butt², M. Jain² and J. Kleijnen ${ }^{3}$
}

\begin{abstract}
Background: Duchenne Muscular Dystrophy (DMD) is a rapidly progressive, lethal neuromuscular disorder, present from birth, which occurs almost exclusively in males. We have reviewed contemporary evidence of burden, epidemiology, illness costs and treatment patterns of DMD.

This systematic review adhered to published methods with information also sought from the web and contacting registries. Searches were carried out from 2005 to June 2015. The population of interest was individuals with clearly defined DMD or their carers.

Results: Nine thousand eight hundred fifty titles were retrieved from searches. Fifty-eight studies were reviewed with three assessed as high, 33 as medium and 22 as low quality. We found two studies reporting birth and four reporting point prevalence, three reporting mortality, 41 reporting severity and/or progression, 18 reporting treatment patterns, 12 reporting quality of life, two reporting utility measures, three reporting costs of illness and three treatment guidelines. Birth prevalence ranged from 15.9 to 19.5 per 100,000 live births. Point prevalence per 100,000 males was for France, USA, UK and Canada, 10.9, 1.9, 2.2 and 6.1 respectively. A study of adult DMD patients at a centre in France found median survival for those born between 1970 and 1994 was 40.95 years compared to 25.77 years for those born between 1955 and 1969. Loss of ambulation occurred at a median age of 12 and ventilation starts at about 20 years. There was international variation in use of corticosteroids, scoliosis surgery, ventilation and physiotherapy. The economic cost of DMD climbs dramatically with disease progression - rising as much as 5.7 fold from the early ambulatory phase to the non-ambulatory phase in Germany.
\end{abstract}

Conclusions: This is the first systematic review of treatment, progression, severity and quality of life in DMD. It also provides the most recent description of the burden, epidemiology, illness costs and treatment patterns in DMD. There are evidence gaps, particularly in prevalence and mortality. People with DMD seem to be living longer, possibly due to corticosteroid use, cardiac medical management and ventilation. Future research should incorporate registry data to improve comparability across time and between countries and to investigate the quality of life impact as the condition progresses.

Keywords: Duchenne, DMD, Epidemiology, Prevalence, Incidence, Burden, Cost

\footnotetext{
* Correspondence: steve@systematic-reviews.com

${ }^{1}$ Kleijnen Systematic Reviews Ltd., Unit 6, Escrick Business Park, Riccall Road,

Escrick, York YO19 6FD, UK

Full list of author information is available at the end of the article
} 


\section{Background}

Duchenne muscular dystrophy (DMD) is a severe, rapidly progressive neuromuscular disorder which belongs to a group of inherited conditions typically characterised by muscle weakening leading to increased disability. There are many different types of muscular dystrophy which vary considerably in severity, age of onset and life expectancy [1]. DMD is the most common and severe affecting 15.9 to 19.5 per 100,000 live births [2, 3] . DMD occurs as a result of mutations in the dystrophin gene which leads to an absence or deficiency of the protein dystrophin and continuous degeneration of muscle fibres. Although primarily an X-linked condition affecting males, some female carriers are symptomatic for the disorder but usually exhibit a milder phenotype.

Initial symptoms such as delayed walking, frequent falls and difficulty running and climbing stairs tend to be first noticeable between the ages of 1 and 3 years with muscles around the calf, pelvis and thigh often affected first and appearing noticeably bulkier than normal. Children with DMD typically need a wheelchair by the age of 8-14 years, as muscle weakening results in loss of ambulation. Once a patient becomes wheelchair bound, certain comorbid complications progress more rapidly including scoliosis and muscular contractures. Scoliosis, which causes the spine to curve sideways and/or forward or backward, leads to additional orthopaedic problems as one shoulder or hip becomes higher than the other leading to potential respiratory problems as the chest cavity reduces. DMD patients can develop symptoms of cardiomyopathy in the late teens, although the disease in this organ has likely started to develop earlier. Cardiomyopathy causes the heart's chambers to enlarge and the walls to get thinner and in the late-teens or early 20 s the condition is associated with breathing problems and once the heart and respiratory muscles are damaged the condition becomes life-threatening. Even with medical care, most people with DMD die from cardiac or respiratory failure before or during their 30s.

Age at diagnosis was not often reported but studies in Italy and Australia reported mean age as 4 years $[4,5]$. DMD can be suspected when a male child shows abnormal muscle function and hypertrophy but tends to be confirmed following additional clinical presentation (including distribution of weakness) and a complete medical and family history. Elevated levels of serum creatine kinase support further diagnostic work-up for DMD. Historically, diagnosis was confirmed by genetic testing and/or muscle biopsy [6] although in practice, muscle biopsy is rarely undertaken. If clinicians are not fully aware of the manifestations of DMD then delays in diagnosis are likely.

There is no cure for DMD and current treatment options focus on alleviation of symptoms and management of complications. There is a recognized urgent need for a therapy that can alter the fundamental course of DMD and findings from this study of burden, epidemiology, costs and treatment should inform and support any future research. This review was originally designed to support a value proposition for a specific new treatment for DMD and the authors feel that publication of findings at this time will be of both interest and importance for any new intervention designed to manage the condition.

\section{Methods}

This systematic review adhered to published methods including those recommended by the Cochrane Collaboration [7] and the Centre for Reviews and Dissemination [8] (York, UK), in order to reduce the risk of bias and error. Information was sought from a literature search, web based searches and through contacting registries and patient organisations.

\section{Research questions}

The remit of our review was to identify, collate and describe contemporary evidence of epidemiology (prevalence and mortality), burden (severity and progression), illness costs (direct and indirect) and treatment patterns (pharmacological and other) of Duchenne muscular dystrophy. Current guidelines were also scrutinised for the latest treatment recommendations.

\section{Literature searches}

Searches were carried out from 2005 to June 2015 in 10 databases to identify information on the epidemiology, prevalence and burden of DMD. Guideline searches were undertaken to identify management and treatment of DMD. A pragmatic internet search was also carried out to look for sources to support evidence gaps in prevalence of DMD. Additionally, email alerts and RSS feeds were set up to ensure the latest research was not missed. Further details of searching methods including example search strategies can be found in Additional file 1: Appendix 1.

The main Embase strategy was independently peer reviewed by a second Information Specialist, using the Canadian Agency for Drugs and Technologies in Health (CADTH) checklist [9].

\section{Methods of study selection}

Titles and abstracts identified through electronic database and web searching were independently screened by two reviewers (drawn from a team of SR, $\mathrm{RL}, \mathrm{AH}, \mathrm{MB}, \mathrm{WJ})$ in order to determine whether they met the criteria for inclusion in the review. During this initial phase of the screening process any references which obviously did not meet the inclusion criteria were excluded. Full paper copies were obtained for all of the remaining references. These 
were then independently examined in detail by two reviewers (drawn from the team above working in pairs). All papers excluded at this second stage of the screening process were documented along with the reasons for exclusion. With respect to both screening stages, any discrepancies between reviewers were resolved through discussion or the intervention of a third reviewer (SR or NA).

\section{Inclusion criteria}

Details are reported in Additional file 2: Appendix 2. In summary, aside from prevalence studies, where the general population (or subsets thereof) was of interest, we included all studies which described the population as DMD, even if details on diagnostic methods were missing. We excluded any studies which only reported on mixed populations (e.g. included Becker Muscular Dystrophy (BMD) or other forms of non-Duchenne Muscular Dystrophy).

Epidemiology and burden of disease outcomes of interest were: point prevalence, birth prevalence, demographic characteristics, clinical characteristics of the disease, mortality, incidence/prevalence of comorbidities and progression of the disease.

Quality of life (QoL) outcomes of interest were: the impact of the disease on quality of life (of patient and caregiver) as measured using a generic and disease specific or symptom specific measures.

Cost of illness outcomes of interest included patient and caregiver costs.

We also sought information about current treatment guidelines and treatment patterns.

Case studies were only included where evidence gaps could remain after consideration of other study types. Countries of interest included those in European Union (EU), South America, North America, Japan and Turkey (following advice from content experts at BioMarin Pharmaceuticals). For guidelines, countries of interest were restricted to EU countries and North America.

The years of interest were 2005 to 2015 inclusive. Due to the large number of papers retrieved and in order to concentrate on the most recent evidence, we decided to focus on records from 2010 onwards. Where evidence gaps existed, we sought records from earlier dates...

Studies were not limited by language or publication status (unpublished or published).

\section{Methods of data extraction}

Data extraction was performed by two reviewers independently (drawn from a team of SR, RL, AH, MB, WJ). Any discrepancies were resolved through discussion or through the intervention of a third reviewer (SR or NA). Exemplar data extraction sheets are presented in Additional file 3: Appendix 3.

\section{Quality of study reporting}

Two reviewers (drawn from a team of SR, RL, AH, $\mathrm{MB}, \mathrm{WJ})$ independently assessed each of the studies using a recommended tool, STROBE [10]. Any discrepancies were resolved through discussion or the intervention of a third reviewer (SR or NA).

Results are presented in Additional file 4: Appendix 4.

\section{Results}

In total, 9,850 titles were retrieved from the database searches and 110 titles were retrieved from the guidelines searches. After deduplication a total of 6,712 titles and abstracts were screened for relevance. Figure 1 summarises the flow of studies through the search and screening process. We excluded 6,431 articles during the title and abstract screening stage and 282 full papers of potentially relevant studies were selected for further examination (after having identified one additional guidelines paper [11] as a result of hand searching).

Of the 282 full papers that were screened, 221 did not meet the inclusion criteria and were excluded. Additionally, four papers with extractable data were part of the same study, meaning that three papers were treated as subsidiary papers to the main one.

Fifty-eight studies (from 61 papers) were therefore included in the review. These are summarised by research question in Additional file 5 with an indication of where follow-up data are available in longitudinal studies.

\section{Prevalence}

Our review found a temporal trend from using both genetic testing and muscle biopsy towards only using genetic testing to identify cases of DMD. Population characteristics in earlier studies may therefore be different to those completed more recently.

Two studies reported birth prevalence and five studies reported point prevalence (see Additional file 4: Appendix 4 Table A8 for characteristics and Table 1 for results). Quality of study reporting was assessed in Additional file 4: Appendix 4 (Table A1 and Table A2). Both birth prevalence studies were judged to be of medium quality but lacked adequate description of study participants $[2,3]$. Two of the point prevalence studies were judged to be of medium quality but again lacked an adequate description of study participants $[12,13]$. The remaining three studies were judged to be of low quality [14-16]. Romitti [14] did not report an adequate description of the study design, nor did it fully describe the eligibility criteria or study participants. Mah [15] failed to adequately describe the eligibility criteria, outcomes or study participants. Bladen [16] also failed to provide adequate descriptions of eligibility criteria and study participants. Thus poor reporting makes it very difficult to assess 


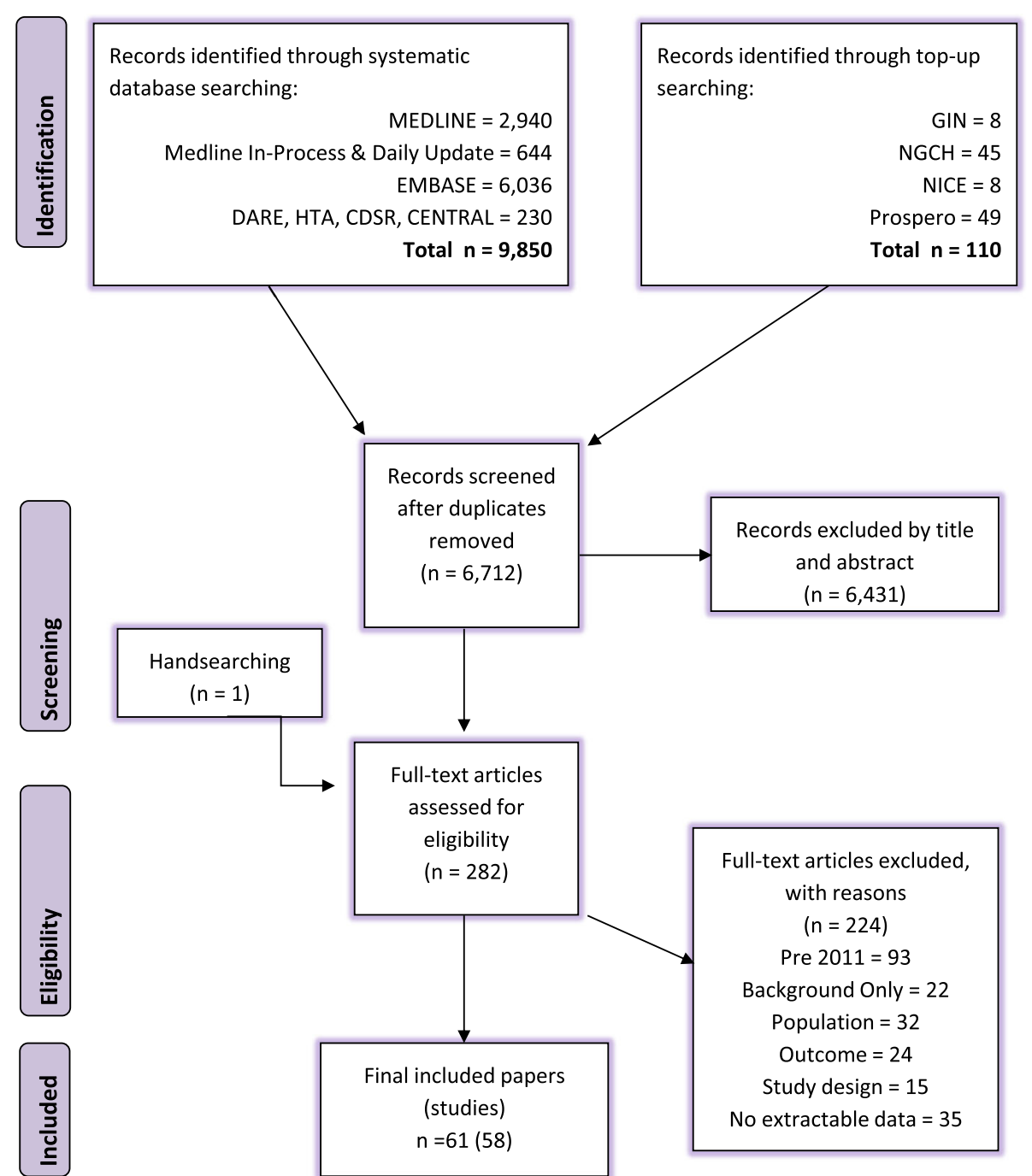

Fig. 1 Flow diagram of included studies

possible changes in the way DMD has been defined over time.

Of the studies reporting birth prevalence, one USA study by Mendell [2] carried out a study on newborn screening for DMD in one of the four main birthing hospitals in Ohio. Creatine kinase (CK) levels in newborn screening blood spots were measured followed by genetic analysis. The authors suggest this approach minimises false-positive testing. Birth prevalence was reported as 15.9 per 100,000 newborn males. A second study, Moat [3] reported on a newborn blood spot screening programme for DMD over a 21 year period in Wales, UK . Again, CK levels in newborn screening blood spots were measured followed by genetic analysis/ muscle biopsy and adjusted for false negatives and cases identified where parents declined to participate in screening. Birth prevalence was reported as 19.5 per 100,000 new-born males.
Of the studies reporting point prevalence, a study by Bladen [16] reported on TREAT-NMD, a worldwide network for neuromuscular diseases which supports new therapies for patients. The network was reported to have many functions including clinical and epidemiological research. From the figure presented, the number of patients per country in the national DMD registry can be estimated and the point prevalence calculated. For France, USA, UK and Canada the point prevalence of DMD was calculated as 10.9, 1.9, 2.2 and 6.1 per 100,000 males, respectively. Mah [15] reported on a population based study of dystrophin mutations in Canada. Of the 773 individuals with dystrophinopathy as confirmed by genetic testing (97\%), muscle biopsy (2\%), or family history (1\%), 529 had DMD. Point prevalence of DMD was reported as 10.3 per 100,000 males aged 0-24 in Canada based on the 2006 consensus. Rasmussen [13] reported on children with neuromuscular disorders from a region of South 
Table 1 Summary of prevalence results by age grouping

\begin{tabular}{|c|c|c|c|c|c|c|}
\hline Age Group & First author \& publication year & Geography & $\begin{array}{l}\text { Number DMD } \\
\text { identified }\end{array}$ & Prevalence date & $\begin{array}{l}\text { Mean prevalence } \\
\text { per } 100,000\end{array}$ & Type of prevalence \\
\hline \multirow[t]{2}{*}{ Newborn } & Mendell, 2012 [2] & Ohio & 6 & $2007-2011$ & 15.9 & \multirow[t]{2}{*}{ Birth } \\
\hline & Moat, 2013 [3] & Wales & 72 & 1990-2011 & 19.5 & \\
\hline \multirow{4}{*}{$\begin{array}{l}\text { Boys aged } \\
5 \text { to } 9\end{array}$} & \multirow[t]{4}{*}{ Romitti, 2015 [14] } & \multirow[t]{4}{*}{ USA } & 111 & 1991-1995 & 14.3 & \multirow[t]{4}{*}{5 - year } \\
\hline & & & 117 & 1996-2000 & 14.6 & \\
\hline & & & 127 & $2001-2005$ & 16.0 & \\
\hline & & & 141 & $2006-2010$ & 11.8 & \\
\hline $\begin{array}{l}\text { Boys aged } \\
5 \text { to } 24\end{array}$ & Romitti, 2015 [14] & USA & 389 & 2010 & 10.2 & Point \\
\hline Males under 18 & Rasmussen, 2012 [13] & SE Norway & 33 & 2005 & 16.2 & \\
\hline Males 0 to 24 & Mah, 2011 [15] & Canada & 529 & 2000-2009 & 10.3 & \\
\hline \multirow[t]{5}{*}{ All Males } & Norwood FL, 2009 [12] & Northern England & 124 & 2007 & 8.3 & \\
\hline & \multirow[t]{4}{*}{ Bladen $2013[16]^{*}$} & France & 3337 & 2012 & 10.9 & \\
\hline & & USA & 2833 & 2012 & 1.8 & \\
\hline & & UK & 666 & 2012 & 2.2 & \\
\hline & & Canada & 1020 & 2012 & 6.1 & \\
\hline
\end{tabular}

*Reported in Bladen [16] but based on web-based registry data

Eastern Norway. Diagnosis was confirmed by genetic testing and/or muscle biopsy. The point prevalence of DMD was 16.2 per 100,000 males under 18 years of age in this region reported on $1^{\text {st }}$ July 2005. Romitti [14] presented population based prevalence estimates for DMD and BMD in 6 US states based on the Muscular Dystrophy Surveillance, Tracking, and Research Network (MD STARnet) as established by the Centers for Disease Control and Prevention. Diagnosis of DMD was based on symptoms and age at onset, creatine kinase value, results of dystrophin mutation analysis testing, muscle biopsy reports, and family history. Point prevalence of DMD was 10.2 per 100,000 males aged 5-24 in 2010.

Few studies reported the prevalence of DMD in relation to an all age male population. However, we did find one study by Norwood [12] which reported a detailed population study of patients with genetic muscle disease in northern England. Although outside of our inclusion criteria, it presented most recent data on total population (without age restriction). The point prevalence was reported as 8.3 per 100,000 males on $1^{\text {st }}$ August 2007 based on 124 cases identified through genetic testing and muscle biopsy.

\section{Mortality}

We identified three studies reporting information on the survival of DMD patients [17-19]. Quality of study reporting was assessed in Additional file 4: Appendix 4 (Table A3). Both Rall [19] and Kieny [20] were found to be of medium quality but neither provided an adequate description of study participants. Passamano [18] was assessed as low quality as it failed to adequately describe study design, outcomes or study participants and it was unclear if the study population was representative of the target population.

These three European long term retrospective cohort studies have each traced patients over a minimum of 30 years. All three studies (one each from Italy, France and Germany) reported median survival between 24 and 26 years. In the French study by Kieny $[17,20]$, median survival (calculated using the Kaplan-Meir model) was reported as 25.8 years for patients born between 1955 and 1969 and 40.9 years for patients born after 1970; the authors suggested that this difference was linked to greater availability of ventilator assistance through tracheotomy in the later birth cohort. In an Italian study by Passamano [18], the percentage overall mortality was assessed for patients when aged 20 and 25 born in either the $1960 s, 1970$ s or 1980s. The study found that for those born in the $1960 \mathrm{~s}, 76.7 \%$ would have died by the age of 20 and $86.5 \%$ by the age of 25 ; for those born in the 1970s, $46 \%$ would have died by the age of 20 and $69.4 \%$ by the age of 25 ; for those born in the 1980 s, $40.2 \%$ would have died by the age of 20 and $50.8 \%$ by the age of 25 . A study in Germany by Rall [19] also looked at patients born in the 1970s and found that median survival was 24 years, although this finding was sensitive to diagnosis method in that subjects with only a clinical diagnosis (as opposed to molecular testing) had a higher (67\%) chance of reaching 24 years. Details of studies reporting mortality are set out in Additional file 4: Appendix 4 Table A9 with results in Table 2. 
Table 2 Mortality results

\begin{tabular}{|c|c|c|c|c|c|c|}
\hline First author \& publication year & Name of subgroup & Country & Number of cases & Median survival & Number of deaths & $\begin{array}{l}\% \text { overall } \\
\text { mortality }\end{array}$ \\
\hline \multirow[t]{3}{*}{ Kieny, 2013 [17] } & Born 1955-1994 & France & 119 & NR & 55 & 27.6 \\
\hline & Born 1955-1969 & & 43 & 25.77 years & NR & NR \\
\hline & Born 1970-1994 & & 76 & 40.95 years & NR & NR \\
\hline \multirow[t]{7}{*}{ Passamano, 2012 [18] } & Born 1961-1990 & Italy & 516 & NR & NR & NR \\
\hline & $\begin{array}{l}\text { Born 1961-1970 } \\
\text { (age 25) }\end{array}$ & & NR & NR & NR & 86.5 \\
\hline & $\begin{array}{l}\text { Born 1971-1980 } \\
\text { (age 25) }\end{array}$ & & NR & $N R$ & NR & 69.4 \\
\hline & $\begin{array}{l}\text { Born 1981-1990 } \\
\text { (age 25) }\end{array}$ & & NR & NR & NR & 50.8 \\
\hline & $\begin{array}{l}\text { Born 1961-1970 } \\
\text { (age 20) }\end{array}$ & & NR & NR & NR & 76.7 \\
\hline & $\begin{array}{l}\text { Born 1971-1980 } \\
\text { (age 20) }\end{array}$ & & $N R$ & $N R$ & NR & 46 \\
\hline & $\begin{array}{l}\text { Born 1981-1990 } \\
\text { (age 20) }\end{array}$ & & NR & NR & NR & 40.2 \\
\hline Rall, 2012 [19] & Born 1970-1980 & Germany & 67 & $\begin{array}{l}\text { Median survival was } 24 \text { years } \\
(21.3-26.7 \mathrm{Cl}) \text { for patients } \\
\text { diagnosed with molecular testing } \\
(n=67) \text {. The probability of reaching } \\
24 \text { years was } 67 \% \text { for subjects with } \\
\text { DMD diagnosed clinically only. }\end{array}$ & NR & NR \\
\hline
\end{tabular}

\section{Severity and progression}

Forty-seven studies reported some information relating to the severity of DMD and/or its progression and 27 of these reported that they identified cases using genetic testing. The quality of reporting of these studies was recorded in Table A4. Three studies were judged to be of high quality [21-23] satisfying all the criteria. The remainder of the studies were medium and low quality, typically not providing adequate information on study participants leading to uncertainty as to whether the population was representative of the target population.

Study characteristics are set out in Additional file 4: Appendix 4 Table A10. Considerable variation in the methods used to measure severity was identified. We found considerable heterogeneity between studies in terms of criteria used to assess ambulatory status, wheelchair usage, mobility, scoliosis, cardiac and respiratory function and intelligence. Two studies reported the distribution of general severity i.e. a summary measure of disease status in the DMD population, both of which were based on ambulatory status as described by Bushby et al [6]. There was a far higher percentage of the German population [23] in the most severe equivalent category i.e. late non-ambulatory and non ambulatory with confinement (stages 4 and 5): $47.6 \%$ versus $35.8 \%$ in the US [24]. It is not clear why this should be the case, although it should be noted that the German study was of better quality and was published more recently. Results are set out in Additional file 4: Appendix 4 Table A11.
Ten studies reported cross-sectional data on loss of ambulation, either as the percentage who have already lost ambulation or mean age at loss of ambulation. Percentage loss of ambulation varied from $32.6 \%$ in a study of the whole DMD population across four continents (Bello [25]) to $56.4 \%$ in a Japanese study (Nakamura [26]) although age of participants was reported in neither study. The relationship with age was shown clearly in a US study by Mayer [27] in that there was no loss of ambulation before age 8 years and progressive loss until age 16-18 years, after which loss was $100 \%$. One French study (Martigne [28]) reported a mean age of ambulation loss of 10 years. Unsurprisingly similar results were found in six studies reporting wheelchair use, four as percentage [29-32] and two as time to first use $[19,33]$. Percentage use and time to use were unsurprisingly similar to those for loss of ambulation.

Eight studies reported mean six minute walking distance (6MWD plus, in some cases, other measures of mobility. 6MWD varied from $288.7 \mathrm{~m}$ reported in Pane [34] for those able to walk less than $350 \mathrm{~m}$ and aged at least 7 years to $428.7 \mathrm{~m}$ in those able to walk at least $350 \mathrm{~m}$ in the same age group. The only international study had an estimate of $361.1 \mathrm{~m}$ for those at least 5 years old (McDonald [22]).

The mean time to climb four stairs was varied between $2.5 \mathrm{~s}$ for those less than 7 years old to $6.6 \mathrm{~s}$ for those at least 7 years old in the international study (McDonald [22]). In the same study, mean $10 \mathrm{~m}$ run/walk time was 4.8 and 7.1 s respectively. 
The percentage of the DMD population with scoliosis was reported in four studies from three countries and one multinational study. The percentage of the DMD population with scoliosis varied between $3.9 \%$ in a Japanese study of males with no age restrictions (Nakamura [26]) and $52.1 \%$ in a French study of boys ranging between 6 and 19 years old (Khirani [35]). The variation with stage of disease was shown in a multinational study in that the percentage was lowest at $16.6 \%$ in those in the early ambulatory stage (median age 7.2 years) and highest at $77.6 \%$ in the late non-ambulatory stage (median age 19.9) (Janssen [36]).

Cardiac function or percentage with cardiomyopathy was reported in six studies. Mean shortening fraction varied from $21.2 \%$ in the whole DMD population (left ventricular shortening fraction) from the US study by Ashwath [37] to 35\% for those at least 10 years old from a US study by Thomas [38]. This variation appears to be consistent with age and thus disease stage. Percentage with cardiomyopathy varied similarly from $21 \%$ in younger boys (mean age (sd); 7.2 (2) years) (Thomas [38]) to $57.3 \%$ in a DMD population aged 10 years or more (Ashwath [37]). One study showed intercountry variation from $41.9 \%$ in Denmark to $52.4 \%$ in the UK in adult populations (Rodger [39]). It is not known whether demographic differences between populations may explain this difference.

Respiratory function, whether measured by percentage on assisted ventilation, time to introduction of ventilation, percentage of predicted Forced Expiratory Volume (ppFEV1) or percentage of predicted Forced Vital Capacity (ppFVC), was reported in 14 studies. The percentage of all DMD patients on assisted ventilation varied very widely from $0 \%$ in a Brazilian study of boys (mean age 11 years) by de Moura [29],0.7\% in a multinational European study (mean age 13 years) by Vry [40] and $22 \%$ in a Japanese study (mean age not reported but most individuals described as less than 20 years old) (Nakamura [26]). Variation by disease progression was shown in the US study by Mayer [27] with a gradual decline from $126.6 \%$ predicted forced vital capacity (FVC) in the under 6 years age group to $7.3 \%$ predicted FVC in those aged 20 to 22 years.

Only one study $(n=4)$ by Khirani [35] in France reported the annual change in percent predicted Forced Vital Capacity (ppFVC). They found a $4.9 \%$ decline in respiratory function for patients with a mean age at baseline of 11.6 years. The percentage on assisted ventilation and age to start of ventilation after long term follow-up were reported in three moderate sized studies (no distinctions were made between night-time, daytime or continuous ventilation). After a mean follow-up of 18.3 years Martigne [28] found that 20\% of study participants in France (mean age at baseline 13.0 years) were on assisted ventilation and the mean age for start of assisted ventilation was 16.8 years. In another French study, Kieny [17] claimed a follow up of 30 years, although the mean follow-up duration was not reported, and reported a much higher percentage of participants on assisted ventilation (65\%) with a median age at start assisted ventilation of 20.1 years. The percentage on ventilation was also found to have increased from $60 \%$ before 1970 to $83 \%$ during and after 1970 with a decrease in the age at start of assisted ventilation from 20.1 to 18.3 years. The median age at start of assisted ventilation was essentially the same (i.e. 20 years) as that reported in the German study by Rall [19]. The authors of this study suggested that prolonged survival of DMD patients born after 1970 was directly associated with increased use of ventilation with tracheotomy especially when performed early. This was the only study to have made such a claim.

Two studies reported measures of intelligence, one reporting a mean score of 86.4 (compared to a mean score of 107.7 for a non-DMD group) on the Wechsler Intelligence Scale for Children-Revised in boys between 6 and 12 years (Lorusso [31]) and one reporting a mean score of 89.5 (compared to 100 for a non-DMD group) on the Bayley III cognitive composite instrument is in boys younger than 3 years from the US (Connolly [41]).

Progression of DMD can be measured in various ways. Those that are reported in the literature include changes in ambulatory status, ambulatory capacity (including $6 \mathrm{MWD}$ ), and respiratory function.

Five studies followed up ambulatory status for those with DMD. Three of these studies began with those that were ambulant, two that followed up for 3 years in Italy by Pane [34] and in Italy and Belgium by Pane [42] and one that followed up for 7 years in the UK by Ricotti [43]. A study by Mah [44] followed up ambulant and non-ambulant boys for 1 year; this was an international study where information was not reported by country. Finally, Soderpalm [45] followed up anyone with DMD regardless of ambulatory status for 4 years in western Sweden.

In a study of boys in Italy (mean age 8.2 years), Mazzone [46] found a 3\% loss in ambulation at 1 year follow-up. Over 3 years, the percentage who lost ambulation varied from $5.2 \%$ for those who with baseline $6 \mathrm{MWD}$ of $\geq 350 \mathrm{~m}$ and $\leq 7$ years old to $64 \%$ with baseline 6MWD of $<350 \mathrm{~m}$ and were $\geq 7$ years old, reported in the follow up study by Pane [34] . In this study, loss of ambulation after 3 years, for combined sub groups, was 29\%. In a study of DMD in Italy and Belgium, loss of ambulation was reported as $2.1 \%$ after 1 year in those who could originally walk $\geq 100 \mathrm{~m}$ (mean age at baseline 7.9 years) (Pane [42]) 
Mah [44] reported that, after 1 year, the percentage loss of ambulation increased from $43 \%$ at baseline to $57.1 \%$ at follow-up (mean age 12.0 at baseline). In a Swedish study, Soderpalm [45] for 18 patients aged between 2 and 19 years reported proportions of nonambulant increasing from 22 to $50 \%$ over a 4 -year mean follow up period. Therefore, it appears that participants in the Mah study may have been at an earlier stage in the disease. Median age for loss of ambulation was estimated at between 12 and 14 years by Ricotti [47] in the UK. Results are set out in Table 3 with changes in 6MWD in Table 4.

We found no evidence on the impact of specific mutations on severity/disease progression.

\section{Treatment patterns}

We found 18 studies reporting treatment patterns for DMD patients. One study was assessed as high quality [23], 12 were assessed as medium and five as low (see Additional file 4: Appendix 4 Table A5) [4, 35, 39, 40, 47]. Typically low and medium quality studies neglected to report a description of the study participants or outcomes.

This section reports on different treatment regimens reported in different studies. Ideally this would be linked to experiences in terms of clinical outcomes; however, this is not possible because of the considerable variation in reporting of outcomes as well as heterogeneity of populations considered. Fourteen studies reported levels of corticosteroid usage, with a further four studies reporting on different aspects of care. International variations in use of corticosteroids, scoliosis surgery, ventilation and physiotherapy were found.

Usage of corticosteroids was found to vary by ethnicity with $67.6 \%$ of white American DMD patients having this treatment as opposed to only $40.5 \%$ of black American DMD patients (Fox, [48]). Characteristics of the studies providing evidence for corticosteroid use are set out in Additional file 4: Appendix 4 Table A12 with variation in use percentages shown in Fig. 2.

We found a number of studies reporting uptake of non-drug therapy. Uptake of scoliosis surgery was reported in one French study reporting that $52 \%$ of DMD patients underwent this surgery between 2001 and 2011 (Khirani [35]).

Another French study by Kieny [17] was the only one to report on uptake of ventilation. The prime focus of the study was to assess life expectancy over the period 1981 to 2011 and the study therefore relates to DMD at all ages. Kieny and others have suggested that ventilator assistance, mostly through tracheotomy, prolongs life expectancy. Although the numbers of cases were fairly low, only $27.9 \%$ of patients born prior to 1970 underwent tracheostomy, whereas this proportion had risen to $47.8 \%$ for patients born after 1980 (an even higher percentage was recorded for patients born between 1970 and 1980 at $58.5 \%$ ).

Rodger [39] reported the most extensive results for non-pharmacological management of DMD patients. The study not only compared and contrasted treatment uptake in Germany, UK, Denmark and Eastern Europe

Table 3 Change in loss of ambulation

\begin{tabular}{|c|c|c|c|c|c|c|c|c|}
\hline $\begin{array}{l}\text { Country/ } \\
\text { countries }\end{array}$ & Name of subgroup & $\begin{array}{l}\text { First author \& } \\
\text { publication year }\end{array}$ & $\begin{array}{l}\text { Sample } \\
\text { size }\end{array}$ & $\begin{array}{l}\text { Mean } \\
\text { age }\end{array}$ & $\begin{array}{l}\text { Loss of } \\
\text { ambulation } \\
(\%)\end{array}$ & $\begin{array}{l}\text { Time point for } \\
\text { follow up }\end{array}$ & $\begin{array}{l}\text { Loss of } \\
\text { Ambulation } \\
\text { (n)@FU }\end{array}$ & $\begin{array}{l}\text { Loss of ambulation } \\
\text { (\%)@FU }\end{array}$ \\
\hline \multirow[t]{7}{*}{ Italy } & $\begin{array}{l}\text { Ambulatory } \\
<350 \text { m(6MWT), <7y }\end{array}$ & Pane, 2014 [34] & 9 & 5.8 & 0 & $3 y$ & 2 & 22.22 \\
\hline & $\begin{array}{l}\text { Ambulatory } \\
\geq 350 \mathrm{~m}(6 \mathrm{MWT}),<7 y\end{array}$ & & 19 & 6.16 & & & 1 & 5.26 \\
\hline & $\begin{array}{l}\text { Ambulatory } \\
<350 \text { m(6MWT), } \geq 7 y\end{array}$ & & 25 & 9.87 & & & 16 & 64.00 \\
\hline & $\begin{array}{l}\text { Ambulatory } \\
\geq 350 \mathrm{~m}(6 \mathrm{MWT}), \geq 7 y\end{array}$ & & 43 & 8.9 & & & 5 & 11.63 \\
\hline & Ambulatory-boys & & 96 & NR & & $1 y$ & 3 & 3.00 \\
\hline & & & & & & $2 y$ & 16 & 17.00 \\
\hline & & & & & & $3 y$ & 27 & 29.00 \\
\hline Italy; Belgium & Ambulatory $\geq 100 \mathrm{~m}$ & Pane, 2014 [42] & 191 & 7.9 & & $1 y$ & 4 & 2.10 \\
\hline NR & Boys & Mah, 2012 [44] & 340 & 12.0 & 43 & & 194 & 57.06 \\
\hline Sweden & All DMD & Soderpalm, 2012 [45] & 24 & $N R$ & 17 & $4 y$ & 9 & 38.00 \\
\hline UK & Boys & Ricotti, 2012 [47] & 400 & & $N R$ & $7 Y$ & $N R$ & $\begin{array}{l}\text { Median loss of ambulation } \\
\text { was } 14 \text { years in Daily versus } \\
12 \text { years in Intermittent } \\
\text { prednisolone }\end{array}$ \\
\hline
\end{tabular}




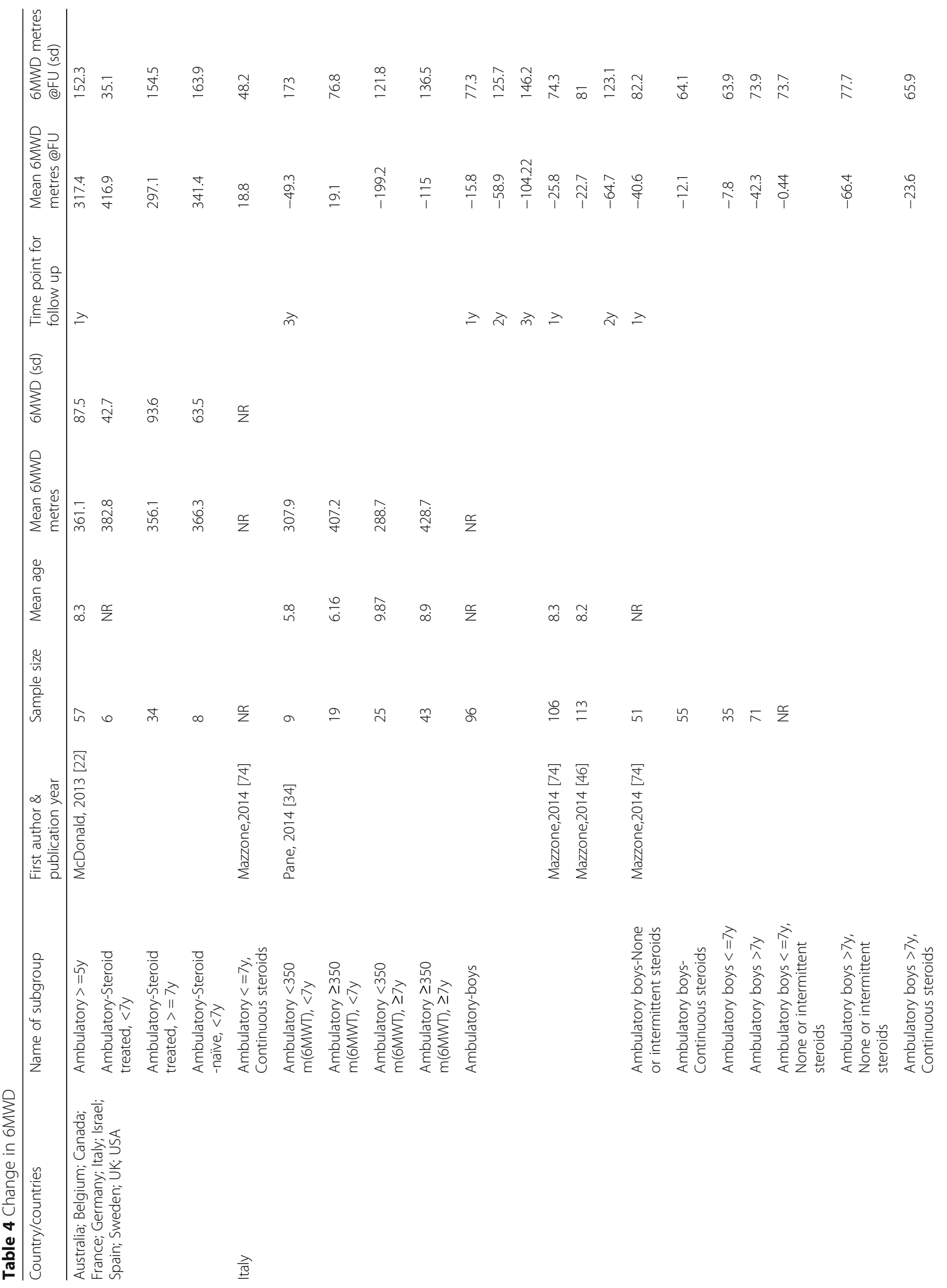




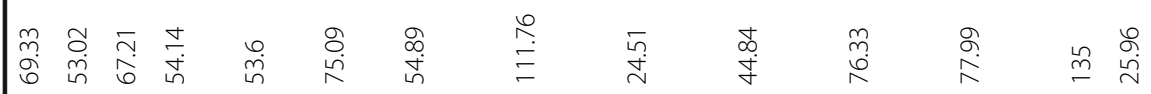

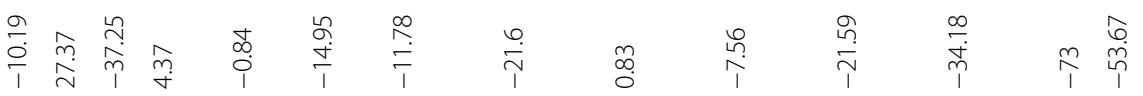

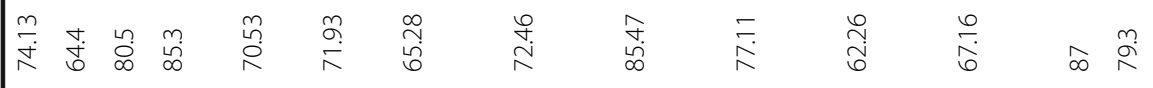

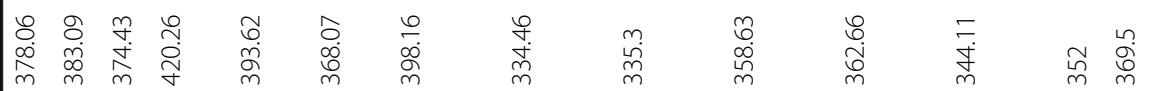

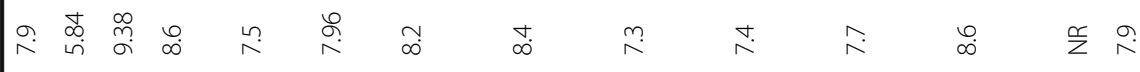

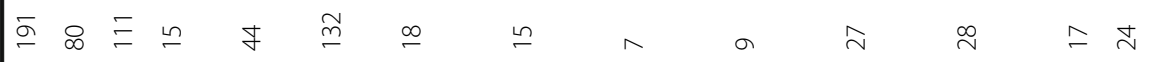

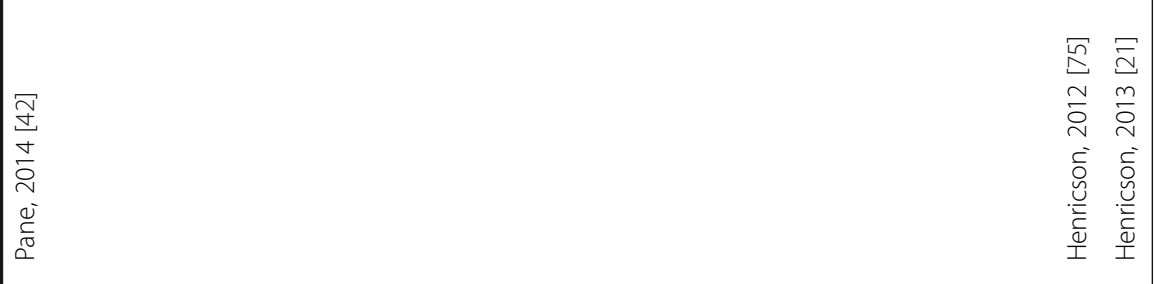

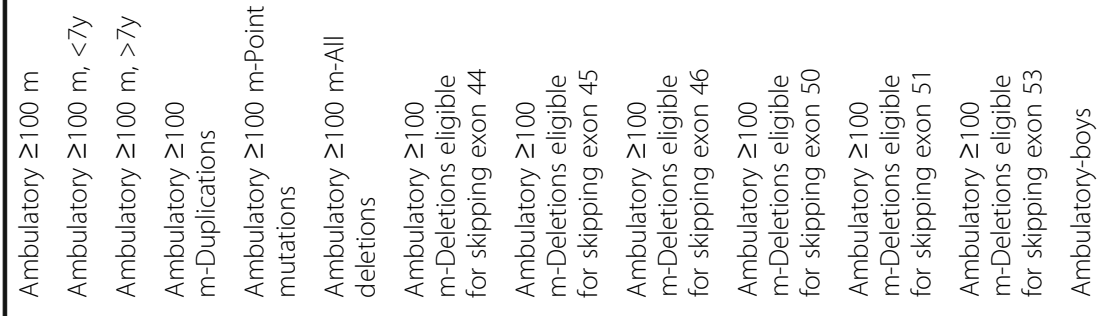




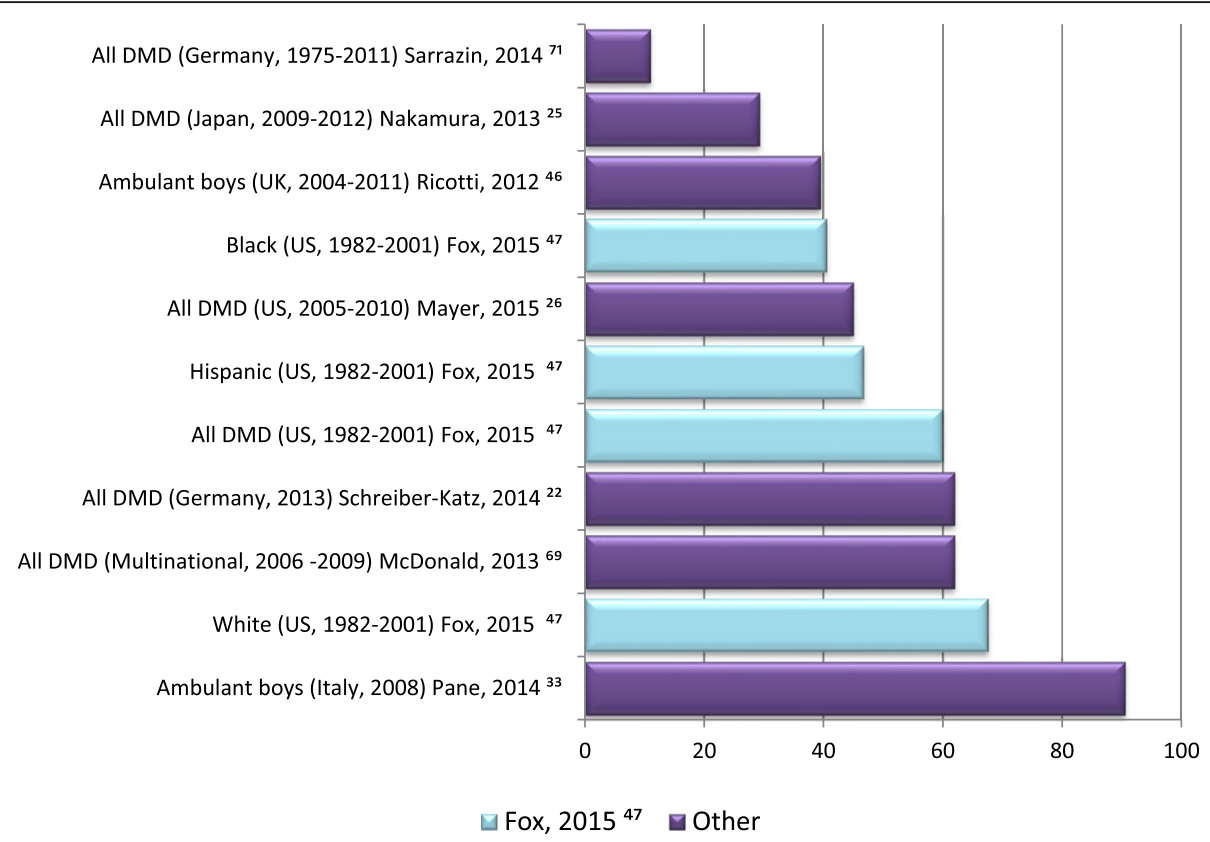

Fig. 2 Variation in corticosteroid use

but also did so separately for children and nonambulatory adults. Use of physiotherapy services was particularly high in Germany and Denmark with 93.2 and $87.8 \%$ of non-ambulatory adults receiving this service, respectively. The comparative percentage for Eastern Europe was $51.3 \%$ with the UK only achieving $21.4 \%$. A similar picture was evident for services received by children with DMD where utilisation was 91.8 and $93.3 \%$ in Germany and Denmark respectively but only 73.5 and $55 \%$ in Eastern Europe and UK respectively. These findings should also be considered alongside the reported weekly utilisation of these services, where the UK also has the lowest levels.

Rodger [39] also reported comparative experience of regular assessments/check-ups for non-ambulatory adults with DMD from UK, Denmark and Germany. The greatest variation was evident for 6 monthly lung function assessment with $45.2 \%$ seen in UK but only $7 \%$ in Denmark, 6 monthly cardiac function assessment with $33.8 \%$ uptake in Germany but only $9.5 \%$ in UK and hospital-based planned check-ups with $67.3 \%$ in Germany and $25.3 \%$ in Denmark. This points to considerable heterogeneity of care patterns from country to country.

\section{Quality of life/utility}

Thirteen studies reported either HRQoL (see Additional file 4: Appendix 4 Table A13) or utilities (see Additional file 4: Appendix 4 Table A14). Parent proxy scores, where collated, were similar to directly elicited values. The quality of reporting of HRQoL studies is presented in Additional file 4: Appendix 4 Table A6. There are 2 high quality studies [21, 23], eight medium quality studies and three low quality studies [49-51]. Typically low and medium quality studies neglected to report a description of the study participants, outcomes or eligibility criteria.

The most frequently used tool for measuring HRQoL was the PedsQL, used in five studies. Three of these studies were conducted in the USA, the largest $(n=406)$ by Uzark [52] in four age groups. Bendixen [53] used two age groups (cut-off at 10 years) and Lim [50] for a cohort of boys and their parents (as proxies). Henricson [21] focused on those who were ambulatory, whereas Schreiber-Katz [23] covered the whole DMD population and subdivided by stage according to ambulatory ability. All studies provided at least the total score and two studies, by Schreiber-Katz [23] and Uzark [52] compared the DMD individual value with one elicited from the parent as proxy. Henricson [21] also used PODCI alongside PedsQL.

One study by Pangalila [54] in adults only, in the Netherlands, compared two different instruments, SF-36 and World Health Organization Quality of Life instrument (WHOQOL-BREF) as well as reporting the Fatigue Severity Score (0 to 5 scale) and Hospital Anxiety and Depression Scale (HADS) (0 to 21 scale). Simon [55] reported the Life Satisfaction Index for Adolescents (LSI-A) in four age groups of boys in Brazil, Baiardini [56] reported the Children Health Questionnaire - Parent Form 50 in Italian boys, Bendixen [51] reported the CAPE (0 to 5 scale) in the US and Canada, de Moura [29] reported the Autoquestionnaire Qualité de vie Enfant 
Imagé (AUQEI) in Brazil and Houwen-van Opstal [57] reported the KIDSCREEN-52 physical domain in the Netherlands. Interestingly, Pangalila [54] concluded that adults with DMD are 'generally satisfied with their overall quality of life.' Also, there was little variation according to stage as shown in both Houwen-van Opstal [57] on the KIDSCREEN instrument and Simon [55] on the LSI-A instrument with no clear trend.

Two papers reported utility values for DMD patients. One large multinational study Landfeldt [58] $(n=770)$ estimated Health Utilities Index (HUI) values (from both the boys and parents perspective) in four countries, Germany, Italy, the UK and the US. In this study the average for all DMD boys was 0.48 (considerably lower than perfect health $(\mathrm{HUI}=1)$ ) but inter-country variation was not large (from 0.43 in the UK to 0.52 in Italy). The other study, reporting utility values, Pentek [49], used EuroQol - 5 Dimensions - 5 Levels (EQ-5DL) for 57 boys with DMD in Hungary. However this study was judged of low quality reporting according to STROBE criteria, largely because of uncertainty surrounding representativeness of those evaluated.

\section{Costs of illness}

We found one high quality study [23], one medium quality [58] and one low quality [32] study providing evidence of the cost of illness for DMD. The main features of these studies are set out in Additional file 4: Appendix 4 Table A15. Taken together, they represent a strong source of evidence of costs accrued at different stages of the condition and across different countries.
The high quality study assessed the burden of illness for German DMD patients and caregivers in 2013 [23]. This study provided an assessment of cost for customised severity groupings (based on Bushby et al [6]), thereby enabling better understanding of the costs associated with progression of the condition. For Schreiber-Katz [23], 2013 total direct medical costs ranged from 4,420 Euro $(€)$ for (stage 1) patients to 68,968 Euro $(€)$ for (stage 5) patients i.e. nearly a 16 fold increase. It is perhaps worth noting that the annual cost of hospitalisation represented between 7\% (stage 4) and 14\% (stage 1) of all direct costs in the Schreiber-Katz [23] study. Further subdivision of direct costs was provided including a detailed breakdown according to service headings (as opposed to staff group headings). The key variation in unit costs associated with progression relate to provision of medical aids costs for (stage 5) which were 104.5 times more than for (stage 1) and costs of respiratory management costs for (stage 5) which were 923.7 times more than for (stage 1). Results are set out in Table 5 .

The study by Landfeldt [58] provided comparative direct costs for Germany, UK, US and Italy in terms of staff groupings as well as service headings. Most inter-country variation in large spend categories was found for physio/OT where spend in the US was 4.5 times that in Italy, psychology where spend in the US was 14.4 times that in either Italy or Germany, specialist physicians where spend in the US was 21.9 times that in Italy and visits to healthcare professionals where spend in the US was seven times that in Italy. The study by Larkindale [32] reported on

Table 5 Summary direct healthcare costs

\begin{tabular}{|c|c|c|c|c|c|c|c|c|c|c|c|c|}
\hline \multirow[t]{2}{*}{ Country } & \multirow[t]{2}{*}{$\begin{array}{l}\text { Name of } \\
\text { subgroup }\end{array}$} & \multirow[t]{2}{*}{$\begin{array}{l}\text { Cost } \\
\text { Year }\end{array}$} & \multirow[t]{2}{*}{ Currency } & \multicolumn{2}{|c|}{$\begin{array}{l}\text { Cost of admission/ } \\
\text { hospitalisation }\end{array}$} & \multicolumn{2}{|c|}{ Cost of medication } & \multicolumn{2}{|c|}{ All medical } & \multicolumn{2}{|c|}{ All Direct Costs } & \multirow[t]{2}{*}{$\begin{array}{l}\text { First author \& } \\
\text { publication year }\end{array}$} \\
\hline & & & & Mean & $\mathrm{LCl} ; \mathrm{UCl}$ & Mean & $\mathrm{LCl} ; \mathrm{UCl}$ & Mean & $\mathrm{LCl} ; \mathrm{UCl}$ & Mean & LCl;UCl & \\
\hline \multirow[t]{7}{*}{ Germany } & $\begin{array}{l}\text { Stage } 1 \text { DMD Age } \\
1 \text { to } 14\end{array}$ & 2013 & \multirow[t]{6}{*}{ Euro $(€)$} & 585 & NR & 172 & NR & NR & NR & 4220 & NR & \multirow[t]{6}{*}{$\begin{array}{l}\text { Schreiber-Katz, } \\
2014 \text { [23] }\end{array}$} \\
\hline & $\begin{array}{l}\text { Stage } 2 \text { DMD Age } \\
3 \text { to } 14\end{array}$ & 2013 & & 804 & NR & 373 & NR & NR & NR & 7629 & NR & \\
\hline & $\begin{array}{l}\text { Stage } 3 \text { DMD Age } \\
10 \text { to } 23\end{array}$ & 2013 & & NR & NR & 344 & NR & NR & NR & 11666 & $N R$ & \\
\hline & $\begin{array}{l}\text { Stage } 4 \text { DMD Age } \\
1 \text { to } 31\end{array}$ & 2013 & & 1540 & NR & 319 & NR & NR & NR & 22989 & $N R$ & \\
\hline & $\begin{array}{l}\text { Stage } 5 \text { DMD Age } \\
11 \text { to } 40\end{array}$ & 2013 & & 6673 & NR & 550 & NR & NR & NR & 68968 & $N R$ & \\
\hline & DMD Age 1 to 42 & 2013 & & 1613 & NR & 330 & NR & NR & NR & 19346 & NR & \\
\hline & DMD Age 9 to 17 & 2012 & \multirow[t]{5}{*}{ US dollar (\$) } & 2080 & $1020 ; 4950$ & 1020 & $770 ; 2000$ & NR & NR & 42360 & $38640 ; 46880$ & \multirow{4}{*}{$\begin{array}{l}\text { Landfeldt(a), } \\
2014[58]\end{array}$} \\
\hline Italy & DMD Age 8 to 17 & 2012 & & 1420 & $900 ; 2470$ & 1550 & $890 ; 4650$ & NR & NR & 23920 & $20420 ; 28300$ & \\
\hline UK & DMD Age 8 to 17 & 2012 & & 2300 & $1500 ; 3720$ & 930 & $820 ; 1070$ & NR & NR & 54160 & $47310 ; 63510$ & \\
\hline \multirow[t]{2}{*}{ US } & DMD Age 9 to 17 & 2012 & & 2220 & $2220 ; 5050$ & 2070 & $1720 ; 2710$ & $N R$ & NR & 54270 & $48740 ; 62220$ & \\
\hline & DMD Age 0 to 64 & 2010 & & 10012 & NR & 2144 & NR & 24007 & NR & $N R$ & $N R$ & $\begin{array}{l}\text { Larkindale, } \\
2014 \text { [32] }\end{array}$ \\
\hline
\end{tabular}


medical costs but without comparative data or comparable cost categorisation.

Indirect costs were also quantified in each of the three cost of illness studies and expressed in terms of non-service costs and co-payments (see Table 6). Schreiber-Katz [23] assessed the costs of time off work and the impact on parents for each of the DMD stages in their study. They observed that (stage 5) patients had costs which were 2.5 times higher than (stage 2) patients in terms of costs of time off work and that (stage 1) patients had costs which were three times higher than (stage 5) patients in terms of impact on parents. Interestingly, taken together, these two forms of indirect costs represent a much greater cost than direct costs for (stage 1) patients $(13,078$ Euro $(€)$ as opposed to 4,220 Euro $(€)$ ) and also a greater cost for (stage 5) patients (32,907 Euro $(€)$ as opposed to 22,989 Euro (€)). The Landfeldt [58] study provided inter-country comparisons of indirect costs. There was broad similarity in terms of time off work and income loss. However, US funding mechanisms explain the relative high cost of insurance premiums. Loss of leisure time was costed as higher in Germany than in the other countries [58]. Information on copayments was also provided as part of the Landfeldt [58] study. Italy has the highest co-payments of all four countries in each of the categories considered. No study estimated cost of lost productivity due to reduced life expectancy.

Social care costs were assessed in all three cost of illness studies for both services and equipment/adaptations - see Tables 7 and 8. The Schreiber-Katz [23] study provided evidence that informal carer and social care costs are positively associated with severity as measured by Stage of DMD. The costs of informal care time were 5.4 times higher for stage 5 patients than for stage 1 . The costs of social care are also 5.4 times higher. In the international comparative study, Landfeldt [58] found broad similarities in the costs of informal carer time but the costs of home help; personal assistants etc. were notably higher in UK than in comparator countries. Information from Schreiber-Katz [23] on travel/car adaptations did not suggest a relationship with DMD progression and the comparative data provided by Landfeldt [58] suggested broad similarity in spend on equipment costs between UK, US and Germany with spend in Italy being noticeably lower.

Finally, out-of-pocket expenses were considered in the Landfeldt [58] study as detailed in Table 9. These clearly represent a considerable cost of illness and there was a degree of similarity between countries.

Table 6 Indirect costs of DMD; non service

\begin{tabular}{|c|c|c|c|c|c|c|c|c|c|c|c|}
\hline \multirow[t]{2}{*}{$\begin{array}{l}\text { Country: Subgroup: } \\
\text { Cost year: Currency }\end{array}$} & \multicolumn{2}{|c|}{ Costs of time off work } & \multicolumn{2}{|c|}{ Income loss } & \multicolumn{2}{|c|}{$\begin{array}{l}\text { Insurance } \\
\text { premiums }\end{array}$} & \multicolumn{2}{|c|}{ Loss of leisure time } & \multicolumn{2}{|c|}{$\begin{array}{l}\text { Impact on } \\
\text { parents }\end{array}$} & \multirow[t]{2}{*}{$\begin{array}{l}\text { First author \& } \\
\text { publication year }\end{array}$} \\
\hline & Mean & $\mathrm{LCl} ; \mathrm{UCl}$ & Mean & $\mathrm{LCl} ; \mathrm{UCl}$ & Mean & $\mathrm{LCl} ; \mathrm{UCl}$ & Mean & $\mathrm{LCl} ; \mathrm{UCl}$ & Mean & $\mathrm{LCl} ; \mathrm{UCl}$ & \\
\hline $\begin{array}{l}\text { Germany: DMD Age } 9 \text { to } \\
\text { 17:2012:US dollar (\$) }\end{array}$ & 20770 & $17670 ; 24250$ & 1190 & $730 ; 1880$ & 150 & $60 ; 290$ & 17910 & $16210 ; 20110$ & NR & NR & $\begin{array}{l}\text { Landfeldt(a), } \\
2014[58]\end{array}$ \\
\hline $\begin{array}{l}\text { Italy: DMD Age } 8 \text { to } \\
\text { 17:2012:US dollar (\$) }\end{array}$ & 18220 & $15430 ; 21380$ & 620 & $310 ; 1130$ & 10 & $0 ; 30$ & 12440 & $10710 ; 14980$ & $N R$ & $N R$ & \\
\hline $\begin{array}{l}\text { UK: DMD Age } 8 \text { to } \\
\text { 17:2012:US dollar (\$) }\end{array}$ & 18700 & $16280 ; 21150$ & 750 & $440 ; 1200$ & 10 & $0 ; 30$ & 13590 & $12410 ; 14980$ & $N R$ & NR & \\
\hline $\begin{array}{l}\text { US: DMD Age } 9 \text { to } \\
\text { 17:2012:US dollar (\$) }\end{array}$ & 21550 & $18490 ; 24720$ & 840 & $500 ; 1360$ & 6210 & $2820 ; 14580$ & 11700 & $10520 ; 12630$ & NR & $N R$ & \\
\hline $\begin{array}{l}\text { US:US DMD All } \\
\text { Age:2010:US dollar (\$) }\end{array}$ & NR & NR & 15481 & NR & $N R$ & NR & $N R$ & NR & $N R$ & $N R$ & $\begin{array}{l}\text { Larkindale, } \\
2014 \text { [32] }\end{array}$ \\
\hline $\begin{array}{l}\text { Germany: DMD Age } 1 \text { to } \\
\text { 42:2013:Euro }(€)\end{array}$ & 21463 & NR & NR & NR & NR & NR & NR & NR & 7220 & NR & $\begin{array}{l}\text { Schreiber-Katz, } \\
2014 \text { [23] }\end{array}$ \\
\hline $\begin{array}{l}\text { Germany: Stage } 1 \text { DMD } \\
\text { Age } 1 \text { to 14:2013:Euro }(€)\end{array}$ & $N R$ & NR & NR & NR & $N R$ & NR & NR & NR & 13078 & NR & \\
\hline $\begin{array}{l}\text { Germany: Stage } 2 \text { DMD } \\
\text { Age } 3 \text { to 14:2013:Euro }(€)\end{array}$ & 11100 & NR & NR & NR & NR & NR & NR & NR & 3855 & NR & \\
\hline $\begin{array}{l}\text { Germany: Stage } 3 \text { DMD } \\
\text { Age } 10 \text { to 23:2013:Euro }(€)\end{array}$ & NR & NR & NR & NR & $N R$ & NR & NR & NR & 8046 & NR & \\
\hline $\begin{array}{l}\text { Germany: Stage } 4 \text { DMD } \\
\text { Age } 1 \text { to 31:2013:Euro }(€)\end{array}$ & 18734 & NR & NR & NR & NR & NR & NR & NR & 7044 & NR & \\
\hline $\begin{array}{l}\text { Germany: Stage } 5 \text { DMD } \\
\text { Age } 11 \text { to 40:2013:Euro (€) }\end{array}$ & 28529 & NR & NR & NR & NR & NR & NR & NR & 4378 & NR & \\
\hline
\end{tabular}


Table 7 Social care expenses; services

\begin{tabular}{|c|c|c|c|c|c|c|c|c|c|}
\hline \multirow[t]{2}{*}{$\begin{array}{l}\text { Country: Subgroup: } \\
\text { Cost year: Currency }\end{array}$} & \multicolumn{2}{|c|}{$\begin{array}{l}\text { Informal carer time/ } \\
\text { Care help }\end{array}$} & \multicolumn{2}{|c|}{$\begin{array}{l}\text { Home help, personal } \\
\text { assistants, nannies, } \\
\text { and transportation } \\
\text { services. }\end{array}$} & \multirow[t]{2}{*}{$\begin{array}{l}\text { Food, travel, } \\
\text { diet etc. }\end{array}$} & \multirow[t]{2}{*}{ Housing } & \multirow[t]{2}{*}{$\begin{array}{l}\text { Work/school } \\
\text { assistance }\end{array}$} & \multirow[t]{2}{*}{$\begin{array}{l}\text { Social care } \\
\text { cost }\end{array}$} & \multirow[t]{2}{*}{$\begin{array}{l}\text { First author \& } \\
\text { publication year }\end{array}$} \\
\hline & Mean & $\mathrm{LCl} ; \mathrm{UCl}$ & Mean & $\mathrm{LCl} ; \mathrm{UCl}$ & & & & & \\
\hline $\begin{array}{l}\text { Germany: DMD Age } 9 \text { to } \\
\text { 17:2012:US dollar (\$) }\end{array}$ & 18530 & $16440 ; 20580$ & 8920 & $6890 ; 12400$ & NR & $N R$ & $N R$ & $N R$ & $\begin{array}{l}\text { Landfeldt(a), } \\
2014[58]\end{array}$ \\
\hline $\begin{array}{l}\text { Italy: DMD Age } 8 \text { to } \\
\text { 17:2013:US dollar (\$) }\end{array}$ & 13160 & $11270 ; 15280$ & 2740 & $1630 ; 5380$ & NR & NR & $N R$ & NR & \\
\hline $\begin{array}{l}\text { UK: DMD Age } 8 \text { to } \\
\text { 17:2014:US dollar (\$) }\end{array}$ & 14340 & 13030;15990 & 19250 & $13240 ; 28670$ & NR & $N R$ & $N R$ & $N R$ & \\
\hline $\begin{array}{l}\text { US: DMD Age } 9 \text { to } \\
\text { 17:2015:US dollar (\$) }\end{array}$ & 13370 & $12060 ; 14930$ & 7610 & $6210 ; 10260$ & $N R$ & $N R$ & $N R$ & $N R$ & \\
\hline $\begin{array}{l}\text { US:US DMD All } \\
\text { Age:2010:US dollar (\$) }\end{array}$ & $N R$ & $N R$ & $3189^{a}$ & $N R$ & 6605 & $N R$ & $N R$ & 12939 & $\begin{array}{l}\text { Larkindale, } \\
2014[32]\end{array}$ \\
\hline $\begin{array}{l}\text { Germany: DMD Age } 1 \text { to } \\
\text { 42:2013:Euro }(€)\end{array}$ & 21279 & $N R$ & $N R$ & $N R$ & NR & 7102 & 883 & 30884 & $\begin{array}{l}\text { Schreiber-Katz, } \\
2014[23]\end{array}$ \\
\hline $\begin{array}{l}\text { Germany: Stage } 1 \text { DMD } \\
\text { Age } 1 \text { to 14:2014:Euro }(€)\end{array}$ & 8303 & $N R$ & $N R$ & $N R$ & NR & 2881 & $N R$ & 11646 & \\
\hline $\begin{array}{l}\text { Germany: Stage } 2 \text { DMD } \\
\text { Age } 3 \text { to 14:2015:Euro }(€)\end{array}$ & 8029 & $N R$ & $N R$ & $N R$ & $N R$ & 83 & 931 & 10684 & \\
\hline $\begin{array}{l}\text { Germany: Stage } 3 \text { DMD } \\
\text { Age } 10 \text { to 23:2016:Euro }(€)\end{array}$ & 19532 & $N R$ & $N R$ & $N R$ & $N R$ & 3303 & 1980 & 29238 & \\
\hline $\begin{array}{l}\text { Germany: Stage } 4 \text { DMD Age } 1 \text { to } \\
\text { 31:2017:Euro }(€)\end{array}$ & 31490 & $N R$ & $N R$ & $N R$ & NR & 14359 & 1481 & 49834 & \\
\hline $\begin{array}{l}\text { Germany: Stage } 5 \text { DMD Age } 11 \text { to } \\
\text { 40:2018:Euro }(€)\end{array}$ & 44443 & $N R$ & $N R$ & $N R$ & $N R$ & 17112 & $N R$ & 62980 & \\
\hline
\end{tabular}

${ }^{\mathrm{a}}$ Described as care help

\section{Guidelines}

Three key sources were identified in respect to guidelines for the treatment of DMD (see Table 10). In 2010, recommendations were made to consider glucocorticoids, including Deflazacort and Prednisone, as first line therapies for DMD patients of 2 years and over whose condition was not improving (Bushby [6]). Glucocorticoid therapy is highly recommended for patients of 6 years and over to slow the decline in muscle strength and function. It is also recommended that patients, in

Table 8 Social care expenses; equipment and adaptations

\begin{tabular}{|c|c|c|c|c|c|c|}
\hline \multirow[t]{2}{*}{ Country: Subgroup: Cost year: Currency } & \multicolumn{2}{|c|}{ Equipment cost } & \multirow{2}{*}{$\begin{array}{l}\text { Moving or } \\
\text { modifying home }\end{array}$} & \multirow{2}{*}{$\begin{array}{l}\text { Purchase or modifying } \\
\text { motor vehicle }\end{array}$} & \multirow{2}{*}{$\begin{array}{l}\text { Travel/car } \\
\text { adaptation }\end{array}$} & \multirow{2}{*}{$\begin{array}{l}\text { First author \& } \\
\text { publication year }\end{array}$} \\
\hline & Mean & $\mathrm{LCl} ; \mathrm{UCl}$ & & & & \\
\hline Germany: DMD Age 9 to 17:2012:US dollar (\$) & 5560 & $4160 ; 7460$ & NR & $N R$ & NR & Landfeldt(a), 2014 [58] \\
\hline Italy: DMD Age 8 to 17:2013:US dollar (\$) & 1850 & $970 ; 4450$ & NR & NR & NR & \\
\hline UK: DMD Age 8 to 17:2014:US dollar (\$) & 7520 & $5690 ; 9790$ & NR & NR & NR & \\
\hline US: DMD Age 9 to 17:2015:US dollar (\$) & 7930 & $6210 ; 10260$ & NR & NR & NR & \\
\hline US:US DMD All Age:2010:US dollar (\$) & $N R$ & NR & 3050 & 1680 & NR & Larkindale, 2014 [32] \\
\hline Germany: DMD Age 1 to 42:2013:Euro (€) & NR & $N R$ & NR & $N R$ & 1510 & Schreiber-Katz, 2014 [23] \\
\hline $\begin{array}{l}\text { Germany: Stage } 1 \text { DMD Age } 1 \text { to } \\
\text { 14:2014:Euro }(€)\end{array}$ & NR & NR & NR & $N R$ & 420 & \\
\hline $\begin{array}{l}\text { Germany: Stage } 2 \text { DMD Age } 3 \text { to } \\
\text { 14:2015:Euro }(€)\end{array}$ & $N R$ & NR & NR & NR & 1300 & \\
\hline $\begin{array}{l}\text { Germany: Stage } 3 \text { DMD Age } 10 \text { to } \\
\text { 23:2016:Euro }(€)\end{array}$ & $N R$ & NR & NR & $N R$ & 4423 & \\
\hline $\begin{array}{l}\text { Germany: Stage } 4 \text { DMD Age } 1 \text { to } \\
\text { 31:2017:Euro }(€)\end{array}$ & $N R$ & $N R$ & NR & $N R$ & 2490 & \\
\hline $\begin{array}{l}\text { Germany: Stage } 5 \text { DMD Age } 11 \text { to } \\
\text { 40:2018:Euro }(€)\end{array}$ & NR & NR & NR & NR & 915 & \\
\hline
\end{tabular}


Table 9 Out-of-pocket expenses

\begin{tabular}{lll}
\hline Country: Subgroup: Cost year: Currency & \multicolumn{2}{l}{ Patient/family cost } \\
\cline { 2 - 3 } & Mean & \multicolumn{1}{l}{ LCl;UCl } \\
\hline Germany: DMD Age 9 to 17:2012:US dollar (\$) & 4830 & $3150 ; 7670$ \\
Italy: DMD Age 8 to 17:2012:US dollar (\$) & 4250 & $480 ; 2350$ \\
UK: DMD Age 8 to 17:2012:US dollar (\$) & 3180 & $2020 ; 5710$ \\
US: DMD Age 9 to 17:2012:US dollar (\$) & 5060 & $3130 ; 8540$ \\
\hline
\end{tabular}

particular those with pre-existing risk factors, are monitored for side effects such as weight gain, growth retardation, bone demineralisation and increased fracture risk. Supplementary guidance for respiratory management of DMD patients was also published. Birnkrant [59] produced supplementary guidance for respiratory management of DMD patients which recommended equipment, procedures, tests, and diagnostic evaluations, emphasising the assessment of hypoventilation and the identification of specific thresholds for forced vital capacity (FVC), peak cough flow, and maximum expiratory pressure. More recently, results of an international collaboration were published (Kinnett [11]). These guidelines highlight the importance of a multidisciplinary approach to the care of DMD patients, addressing the primary and secondary manifestations of the condition including use of corticosteroids, coronary care, pulmonary care, physical therapy, surgical considerations and psychosocial care.

\section{Discussion}

We conducted a systematic review of contemporary (from 2010) evidence of burden, epidemiology, illness costs, treatment patterns and guidelines for DMD. In total, 9,850 titles were retrieved from searches. Fifty-eight studies were reviewed for reporting quality with three assessed as high quality, 33 as medium quality and 22 low quality.

Two studies reported birth prevalence from newborn screening programmes and five studies reported point prevalence. There appears to be a trend, over time, from using both genetic testing and muscle biopsy towards only using genetic testing in diagnosis which means that caution is required when comparing studies. This problem is exacerbated by inadequate descriptions of eligibility criteria and participants.

We found three studies on mortality [17-19]. People seem to be living longer with the condition. This is attributed to the widespread prescribing of corticosteroids, improved access to ventilation and the publication of more thorough and specific guidelines of care. For example, a French study [17] found that median survival for those born between 1970 and 1994 was 40.95 years compared to a mean lifespan of 25.77 years for those born between 1955 and 1969. Diagnosis method was also shown to be related to survival with molecular testing associated with a higher mortality than clinical only [19]. This is could have a number of implications, one being that the improvement in survival in those patients with true DMD, at least according to molecular testing, will never be known. As Kieny [17] points out in France: 'Certainty of diagnosis was impossible before 1987, and therefore many patients did not initially have a definitive diagnosis.' (p.444) Uncertainty in diagnosis would of course affect the ability to estimate prevalence as well.

We found forty one studies reporting aspects of disease severity and/or its progression. The prevalent DMD population has considerable dependency in that between $22 \%$ [45] and 56\% [26] are likely to have lost ambulation and between 27\% [24] and 57\% [37] have cardiomyopathy. Severity clearly increases with age with a median of around 12 years for loss of ambulation [5] and about 20 years for start of ventilation [17]. Natural history is further explained by consideration of sub groups. The study by Pane [34] found that, over 3 years, the percentage loss of ambulation in those who were originally ambulant varied from $5.2 \%$ for those who could originally walk at least $350 \mathrm{~m}$ ( $<7$ years old $)$ to $64 \%$ for those who could originally walk less than $350 \mathrm{~m}$ ( $\geq 7$ years old). One study undertaken in France [35] provided evidence of changing respiratory function which might be used to inform assessment of function/quality of life as disease progresses. Comparison of studies is hindered by variation in method of diagnosis and most studies inadequately reported participant characteristics.

Treatment patterns were reported in fourteen studies, which showed international variation in use of corticosteroids, scoliosis surgery, ventilation and physiotherapy. We also noted considerable variation in access to corticosteroids between different ethnic groupings as described by Fox [48]. Again, studies often failed to adequately report participant characteristics.

Thirteen studies reported either HRQoL or utilities. The most frequently used tool for measuring HRQoL was the PedsQL which was used in five studies [21, 23, 50, 52, 53] and, for utilities, HUI was calculated for Germany,Italy, UK and US populations in Landfeldt [58]. These measures could be considered when designing future studies although researchers should be aware that some measures reportedly correlate better with disease progression than others. For example there is evidence to suggest that the generic PedsQL does not correlate well with progression of disease in DMD [60]. There may be a trade-off between sensitivity of measurement tool and compatibility with historical research. However, it is also interesting to speculate that lack of change in self-reported quality of life with stage that 


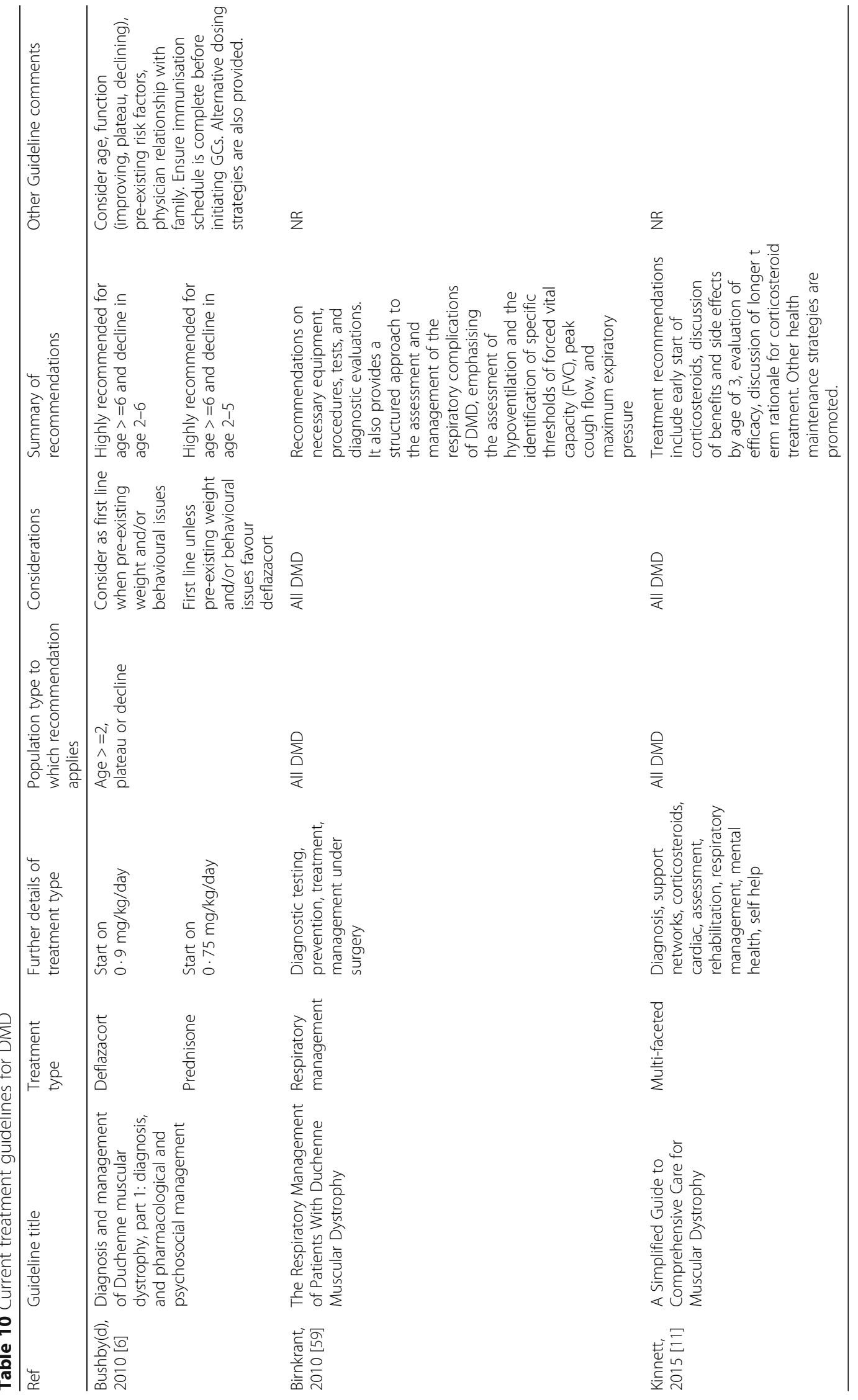


was observed in two studies is not related to insensitivity of instrument, but reflects the stability irrespective of deterioration in physical status [55, 57]. This might reflect adaptation, which is perhaps why parents might produce lower estimates as shown in Houwen-van Opstal [57].

Indirect costs (due to loss of productivity) appear higher than direct costs (of health or social care) for early stage patients and late stage patients but not necessarily for intermediate stages [23], which highlights the importance of staging to inform co-ordinated financial planning of health and social care. However, these findings are based on only one study.

The main strength of our approach was that it used established systematic review methods to consider a broad range of characteristics of disease impact. The main potential limitation of our approach was in its restriction to published and unpublished evidence from 2011 to 2015. This restriction was imposed because all things being equal, contemporary evidence is of much greater relevance than historic evidence. Also more recent studies should have a better diagnosis procedure, distinguish better between BMD and DMD and be more representative of the DMD population. Nevertheless, although recency is important, it might be argued that our search missed older studies and we identified very few studies of prevalence, incidence and mortality which have been published since 2010. However, a comparison to two systematic reviews of epidemiology from 2014 (Theadom [61] and Mah [62]) revealed virtually no studies in the 5 years prior to 2010 (only a household survey in Egypt 2005 and an abstract of a study of practitionerreferrals in Portugal in 2006). A recent systematic review of cost of illness evidence in rare diseases (Angelis [63]) also failed to identify any contemporary cost of illness studies for DMD, which gives us some confidence that most relevant studies have been identified in our review. We were unable to identify any systematic reviews of treatment, progression, severity or utility, to the best of our knowledge, our study is the first to cover these aspects in a systematic way.

Evidence gaps (particularly in regard to prevalence, life expectancy and treatment patterns) might eventually be filled with the emergence of registries. TREAT-NMD is a web-based community of researchers and those with special interests in neuromuscular diseases which acts as a portal for registries. The network was launched in January 2007 and their website contains contact details for 49 separate national registries across all continents (http://www.treatnmd.eu/ [64]). As more "real-time" information is collated it may become increasingly common to undertake prevalence studies using registry data. Other important sources include ongoing natural history studies run by The Cooperative International Neuromuscular Research Group (CINRG).

\section{Recommendations}

We suggest that, as well as natural history studies, patient registries should be considered as a future source of data to estimate prevalence, treatment patterns, effectiveness and to explore variation in severity, progression and mortality. Registries offer a number of key advantages over other forms of primary research in that they largely use a consistent set of criteria (potentially at an international level), they can be up-to-date and they offer potential for cross-matching of patient characteristics and other clinical indicators. Feasibility studies should address coverage levels (as not everyone in a location may be registered) and also data quality assurance issues (e.g. to avoid double-counting of patients and/or means of updating for new cases and deaths).

We also recommend that future studies, which purport to measure overall burden of the condition, fully account for DMD in all age groups and severity/stages of disease. There are very few prevalence studies and no comparability between them because they relate to different denominator populations (typically defined by different age groupings). In particular, there is a need to focus on prevalence in relation to the whole male population, thereby reflecting the changing age profile of those with the condition. Such studies offer the best potential to fully capture burden levels in an entire economy or location and ultimately to improve clinical awareness.

Whilst we found reasonable quality evidence about the cost of illness, only one study conducted a between country comparison [58]. Also, there is a need to relate this to severity/stage of disease, thereby enabling researchers to fully capture the cost consequences of treatment modifications that alter progression of the condition (including survival). We would recommend further research into the implications of quality of life for comorbid conditions like scoliosis in patients with DMD, alongside associated costs. Similarly, quality of life of carers remains under-researched.

One final recommendation, which pertains to all study types, is greater standardisation of reporting: many studies suffered from poor reporting of eligibility criteria or study participant characteristics.

\section{Conclusions}

From a systematic review, fifty eight studies (published since 2010) were found that examined DMD in terms of epidemiology, cost, quality of life and guidelines. There are important evidence gaps, particularly in measuring prevalence and mortality, although people seem to be living longer with the condition, which may be partially as a result of more widespread prescribing of corticosteroids, improved access to ventilation and development and publication of more specific and thorough care 
guidelines. Increased longevity means that studies of prevalence based only on younger populations will become less representative of the disease burden of DMD. Evidence for wider populations as opposed to specific age/ambulatory status sub groupings should become increasingly more relevant, with studies in older populations with advanced progression currently underrepresented.

Disease severity in the prevalent DMD population also appears to be high in that at any given time and any given country between 22 and 56\% are likely to have lost ambulation and between 27 and 57\% have cardiomyopathy. Severity clearly increases with age with a median of around 12 years for loss of ambulation and about 20 years to start ventilation.

Comparability of evidence on changing prevalence and mortality is hampered by changing case definitions with a trend from using both genetic testing and muscle biopsy towards only using genetic testing.

Indirect costs are a significant feature of this condition and should have a role in informing appropriate care packaging and co-ordinated financial planning of health and social care. Per capita cost burden increases with disease progression. The main recommendations, arising from this systematic review, are for the increased collection and use of registry data to increase comparability across time and between countries.

\section{Additional files}

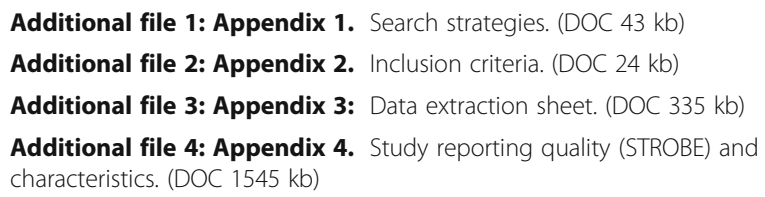

Additional file 5: Summary of included studies by research question [64-73]. (DOC $462 \mathrm{~kb}$ )

\begin{abstract}
Abbreviations
6mwd: Six Metres Walking Distance; BMD: Becker muscular dystrophy; CADTH: Canadian Agency for Drugs and Technologies in Health; CAPE: Children's Assessment of Participation and Enjoyment; CDSR: Cochrane database of systematic reviews; CENTRAL: Cochrane Central Register of Controlled Trials; CK: Serum creatine-kinase (CK); DARE: Database of abstracts of reviews of effects; DMD: Duchenne muscular dystrophy; EQ-5D: EuroQol - 5 Dimensions; EQ-5D-5 L: EuroQol - 5 Dimensions - 5 Levels; ER: Emergency room; EU: European Union; GIN: International Guidelines Network Library; HRQOL: Health related quality of life; HTA: Health technology assessment; NHS EED: NHS economic evaluation database; NHS: National health service; NM: Neuromuscular; PedsQL: Paediatric Quality of Life; PODCl: The Pediatric Outcomes Data Collection Instrument; ppFEV $_{1}$ : Percentage of predicted Forced Expiratory Volume; ppFVC: Percentage of predicted Forced Vital Capacity; QoL: Quality of life; sd: Standard Deviation; STROBE: Strengthening the Reporting of Observational Studies in Epidemiology; TREAT-NMD: Translational Research in Europe-Assessment and Treatment of Neuromuscular Diseases; UK: United Kingdom; USA: United States of America
\end{abstract}

\section{Acknowledgments}

This study was funded by BioMarin. BioMarin contributed to the conception and design of the study, however, KSR retained editorial control. The authors would like to thank Katherine Hendrix and David Wilson for their helpful comments on the manuscript. Finally, we would like to thank other members of the team involved in screening and data extraction of papers, namely Malgorzata Bala (MB), Adrian Hernandez (AH) and Wilco Jacobs (WJ) who worked alongside study authors SR, NA, RL and MW on these aspects.

\section{Funding}

BioMarin paid KSR for the costs of preparing the publication however KSR retained editorial control.

\section{Availability of data and materials}

The data that support the findings of this study are available from KSR Ltd, UK but restrictions apply to the availability of these data, which were used under license for the current study, and so are not publicly available. Data are however available from the authors upon reasonable request and with permission of BioMarin Pharmaceuticals.

\section{Authors' contributions}

$N A, T B, M J, R L, J K$, and SR contributed to conception and design of the study. SdK designed and carried out search strategies. NA, TB, MW, RL and SR were responsible for acquisition, analysis and interpretation of data. NA, SdK, JK, SR RL and MW drafted the manuscript. TB and MJ contributed data. All authors read, critically revised and approved the final manuscript.

\section{Competing interests}

NA, SdK, RL, SL, SR and MW are employed by Kleijnen Systematic Reviews (KSR) Ltd, UK and all declare no conflict of interest. JK is the director of KSR Ltd. TB and MJ receive financial support/salaries as employees of BioMarin Pharmaceuticals.

\section{Consent for publication}

Not applicable

Ethics approval and consent to participate

Not applicable

\section{Publisher's Note}

Springer Nature remains neutral with regard to jurisdictional claims in published maps and institutional affiliations.

\section{Author details}

${ }^{1}$ Kleijnen Systematic Reviews Ltd., Unit 6, Escrick Business Park, Riccall Road, Escrick, York YO19 6FD, UK. 'BioMarin Europe Ltd., 164 Shaftesbury Ave, London WC2H 8HL, UK. ${ }^{3}$ School for Public Health and Primary Care, Maastricht University, Maastricht, The Netherlands.

Received: 13 October 2016 Accepted: 12 April 2017

Published online: 26 April 2017

\section{References}

1. Mercuri E, Muntoni F. Muscular dystrophies. Lancet. 2013;381(9869):845-60.

2. Mendell JR, Shilling C, Leslie ND, Flanigan KM, al-Dahhak R, Gastier-Foster J, Kneile K, Dunn DM, Duval B, Aoyagi A, Hamil C, Mahmoud M, Roush K, Bird L, Rankin C, Lilly H, Street N, Chandrasekar R, Weiss RB. Evidence-based path to newborn screening for Duchenne muscular dystrophy. Ann Neurol. 2012; 71(3):304-13.

3. Moat SJ, Bradley DM, Salmon R, Clarke A, Hartley L. Newborn bloodspot screening for Duchenne muscular dystrophy: 21 years experience in Wales (UK). Eur J Hum Genet. 2013;21(10):1049-53.

4. Magri F, Govoni A, D’Angelo MG, Del Bo R, Ghezzi S, Sandra G, Turconi AC, Sciacco M, Ciscato P, Bordoni A, Tedeschi S, Fortunato F, Lucchini V, Bonato S, Lamperti C, Coviello D, Torrente Y, Corti S, Moggio M, Bresolin N, Comi GP. Genotype and phenotype characterization in a large dystrophinopathic cohort with extended follow-up. J Neurol. 2011;258(9):1610-23.

5. Davidson ZE, Ryan MM, Kornberg AJ, Sinclair K, Cairns A, Walker KZ, Truby H. Observations of body mass index in Duchenne muscular dystrophy: a longitudinal study. Eur J Clin Nutr. 2014;68(8):892-7. 
6. Bushby K, Finkel R, Birnkrant DJ, Case LE, Clemens PR, Cripe L, Kaul A, Kinnett K, McDonald C, Pandya S, Poysky J, Shapiro F, Tomezsko J, Constantin C, Group DMDCCW. Diagnosis and management of Duchenne muscular dystrophy, part 1: diagnosis, and pharmacological and psychosocial management. Lancet Neurol. 2010;9(1):77-93.

7. Higgins JPT, Green S, editors, Cochrane handbook for systematic reviews of interventions. Version 5.1.0 [updated March 2011]: The Cochrane Collaboration. 2011. Available from: http://www.cochrane-handbook.org/. Accessed 23 Mar 2011.

8. Centre for Reviews and Dissemination. Systematic Reviews: CRD's guidance for undertaking reviews in health care. York: University of York; 2009. accessed 23.3.11.

9. Canadian Agency for Drugs and Technologies in Health. CADTH peer review checklist for search strategies. Ottawa: CADTH; 2013. accessed 17.7.13.

10. von Elm E, Altman DG, Egger M, Pocock SJ, Gotzsche PC, Vandenbroucke $J P$. The Strengthening the Reporting of Observational Studies in Epidemiology (STROBE) statement: guidelines for reporting observational studies. J Clin Epidemiol. 2008;61(4):344-9.

11. Kinnett K, Rodger S, Vroom E, Furlong P, Aartsma-Rus A, Bushby K. Imperatives for Duchenne MD: a simplified guide to comprehensive care for Duchenne muscular dystrophy. PLoS Curr. 2015;7. https:/www.ncbi.nlm.nih. gov/pmc/articles/PMC4542198/.

12. Norwood FL, Harling C, Chinnery PF, Eagle M, Bushby K, Straub V. Prevalence of genetic muscle disease in northern England: in-depth analysis of a muscle clinic population. Brain. 2009;132(Pt 11):3175-86.

13. Rasmussen M, Risberg K, Vollo A, Skjeldal OH. Neuromuscular disorders in children in south-eastern Norway. J Pediatr Neurol. 2012;10(2):95-100.

14. Romitti PA, Zhu Y, Puzhankara S, James KA, Nabukera SK, Zamba GK, Ciafaloni E, Cunniff C, Druschel CM, Mathews KD, Matthews DJ, Meaney FJ, Andrews JG, Conway KM, Fox DJ, Street N, Adams MM, Bolen J, STARnet MD. Prevalence of Duchenne and Becker muscular dystrophies in the United States. Pediatrics. 2015;135(3):513-21.

15. Mah JK, Selby K, Campbell C, Nadeau A, Tarnopolsky M, McCormick A, Dooley JM, Kolski H, Skalsky AJ, Smith RG, Buckley D, Ray PN, Yoon G. A population-based study of dystrophin mutations in Canada. Can J Neurol Sci. 2011:38(3):465-74.

16. Bladen CL, Rafferty K, Straub V, Monges S, Moresco A, Dawkins H, Roy A, Chamova T, Guergueltcheva V, Korngut L, Campbell C, Dai Y, Barisic N, Kos T, Brabec P, Rahbek J, Lahdetie J, Tuffery-Giraud S, Claustres M, Leturca F, Ben Yaou R, Walter MC, Schreiber O, Karcagi V, Herczegfalvi A, Viswanathan V, Bayat F, de la Caridad Guerrero Sarmiento I, Ambrosini A, Ceradini F, et al. The TREAT-NMD Duchenne muscular dystrophy registries: conception, design, and utilization by industry and academia. Hum Mutat. 2013;34(11):1449-57.

17. Kieny $\mathrm{P}$, Chollet $\mathrm{S}$, Delalande $\mathrm{P}$, Le Fort M, Magot A, Pereon Y, Perrouin Verbe B. Evolution of life expectancy of patients with Duchenne muscular dystrophy at AFM Yolaine de Kepper centre between 1981 and 2011. Ann Phys Rehabil Med. 2013;56(6):443-54.

18. Passamano L, Taglia A, Palladino A, Viggiano E, D'Ambrosio P, Scutifero M, Rosaria Cecio M, Torre V, DE Luca F, Picillo E, Paciello O, Piluso G, Nigro G, Politano L. Improvement of survival in Duchenne muscular dystrophy: retrospective analysis of 835 patients. Acta Myol. 2012;31(2):121-5.

19. Rall S, Grimm T. Survival in Duchenne muscular dystrophy. Acta Myol. 2012; 31(2):117-20.

20. Kieny P. Evolution of life expectancy of patients with Duchenne muscular dystrophy at AFM Yolaine de Kepper centre between 1981 and 2011, Evolution de l'esperance de vie des patients atteints de dystrophie musculaire de Duchenne au centre AFM Yolaine de Kepper entre 1981 et 2011. [French, English] Paper presented at 27e Congrès de Médecine Physique et de Réadaptation; 19-20 Oct 2012; Toulouse: France. Ann Phys Rehabil Med. 2012;55:e204-6.

21. Henricson E, Abresch R, Han JJ, Nicorici A, Goude Keller E, de Bie E, McDonald CM: The 6-minute walk test and person-reported outcomes in boys with Duchenne muscular dystrophy and typically developing controls: longitudinal comparisons and clinically-meaningful changes over one year. PLoS Curr. 2013;5. https://www.ncbi.nlm.nih.gov/pubmed/ 23867975.

22. McDonald CM, Henricson EK, Abresch RT, Florence JM, Eagle M, Gappmaier E, Glanzman AM, Group PG-DS, Spiegel R, Barth J, Elfring $G$, Reha A, Peltz $S$. The 6-minute walk test and other endpoints in Duchenne muscular dystrophy: longitudinal natural history observations over 48 weeks from a multicenter study. Muscle Nerve. 2013;48(3):343-56.

23. Schreiber-Katz O, Klug C, Thiele S, Schorling E, Zowe J, Reilich P, Nagels KH, Walter MC. Comparative cost of illness analysis and assessment of health care burden of Duchenne and Becker muscular dystrophies in Germany. Orphanet J Rare Dis. 2014;9:210.

24. Spurney C, Shimizu R, Morgenroth LP, Kolski H, Gordish-Dressman H, Clemens PR, Investigators C. Cooperative International Neuromuscular Research Group Duchenne Natural History Study demonstrates insufficient diagnosis and treatment of cardiomyopathy in Duchenne muscular dystrophy. Muscle Nerve. 2014;50(2):250-6.

25. Bello L, Kesari A, Gordish-Dressman H, Cnaan A, Morgenroth LP, Punetha J, Duong T, Henricson EK, Pegoraro E, McDonald CM, Hoffman EP, Cooperative International Neuromuscular Research Group I. Genetic modifiers of ambulation in the Cooperative International Neuromuscular Research Group Duchenne Natural History Study. Ann Neurol. 2015;77(4):684-96.

26. Nakamura H, Kimura E, Mori-Yoshimura M, Komaki H, Matsuda Y, Goto K, Hayashi YK, Nishino I, Takeda S, Kawai M. Characteristics of Japanese Duchenne and Becker muscular dystrophy patients in a novel Japanese national registry of muscular dystrophy (Remudy). Orphanet J Rare Dis. 2013;8:60.

27. Mayer OH, Finkel RS, Rummey C, Benton MJ, Glanzman AM, Flickinger J, Lindstrom BM, Meier T. Characterization of pulmonary function in Duchenne muscular dystrophy. Pediatr Pulmonol. 2015;50(5):487-94.

28. Martigne L, Salleron J, Mayer M, Cuisset JM, Carpentier A, Neve V, Tiffreau V, Guimber D, Gottrand F. Natural evolution of weight status in Duchenne muscular dystrophy: a retrospective audit. Br J Nutr. 2011;105(10):1486-91.

29. de Moura MC, Wutzki HC, Voos MC, Resende MB, Reed UC, Hasue RH. Is functional dependence of Duchenne muscular dystrophy patients determinant of the quality of life and burden of their caregivers? Arq Neuropsiquiatr. 2015;73(1):52-7.

30. Magri F, Del Bo R, D'Angelo MG, Govoni A, Ghezzi S, Gandossini S, Sciacco M, Ciscato P, Bordoni A, Tedeschi S, Fortunato F, Lucchini V, Cereda M, Corti S, Moggio M, Bresolin N, Comi GP. Clinical and molecular characterization of a cohort of patients with novel nucleotide alterations of the Dystrophin gene detected by direct sequencing. BMC Med Genet. 2011;12:37.

31. Lorusso ML, Civati F, Molteni M, Turconi AC, Bresolin N, D'Angelo MG. Specific profiles of neurocognitive and reading functions in a sample of 42 Italian boys with Duchenne muscular dystrophy. Child Neuropsychol. 2013; 19(4):350-69.

32. Larkindale J, Yang W, Hogan PF, Simon CJ, Zhang Y, Jain A, Habeeb-Louks EM, Kennedy A, Cwik VA. Cost of illness for neuromuscular diseases in the United States. Muscle Nerve. 2014;49(3):431-8.

33. Selsby JT. Increased catalase expression improves muscle function in $\mathrm{mdx}$ mice. Exp Physiol. 2011;96(2):194-202.

34. Pane M, Mazzone ES, Sivo S, Sormani MP, Messina S, D'Amico A, Carlesi A, Vita G, Fanelli L, Berardinelli A, Torrente Y, Lanzillotta V, Viggiano E, DA P, Cavallaro F, Frosini S, Barp A, Bonfiglio S, Scalise R, De Sanctis R, Rolle E, Graziano A, Magri F, Palermo C, Rossi F, Donati MA, Sacchini M, Arnoldi MT, Baranello G, Mongini T, et al. Long term natural history data in ambulant boys with Duchenne muscular dystrophy: 36-month changes. PLoS One. 2014;9(10):e108205.

35. Khirani S, Ramirez A, Aubertin G, Boule M, Chemouny C, Forin V, Fauroux B. Respiratory muscle decline in Duchenne muscular dystrophy. Pediatr Pulmonol. 2014:49(5):473-81.

36. Janssen MM, Bergsma A, Geurts AC, de Groot IJ. Patterns of decline in upper limb function of boys and men with DMD: an international survey. [Erratum appears in J Neurol. 2014 Jul;261 (7):1289-90]. J Neurol. 2014;261(7): 1269-88.

37. Ashwath ML, Jacobs IB, Crowe CA, Ashwath RC, Super DM, Bahler RC. Left ventricular dysfunction in duchenne muscular dystrophy and genotype. Am J Cardiol. 2014;114(2):284-9.

38. Thomas TO, Morgan TM, Burnette WB, Markham LW. Correlation of heart rate and cardiac dysfunction in Duchenne muscular dystrophy. Pediatr Cardiol. 2012:33(7):1175-9.

39. Rodger S, Woods KL, Bladen CL, Stringer A, Vry J, Gramsch K, Kirschner J, Thompson R, Bushby K, Lochmuller H. Adult care for Duchenne muscular dystrophy in the UK. J Neurol. 2015;262(3):629-41.

40. Vry J, Gramsch K, Bushby K, Lochmuller H, Rodger S, Steffensen B, Rahbek J, Kirschner J: Current care practice in Duchenne muscular dystrophy in Europe- 
results of the CARE-NMD cross-sectional survey. Neuropediatrics. 2013;44(02): FV16_03.

41. Connolly AM, Florence JM, Cradock MM, Malkus EC, Schierbecker JR, Siener CA, Wulf CO, Anand P, Golumbek PT, Zaidman CM, Philip Miller J, Lowes LP, Alfano LN, Viollet-Callendret L, Flanigan KM, Mendell JR, McDonald CM, Goude E, Johnson L, Nicorici A, Karachunski Pl, Day JW, Dalton JC, Farber JM, Buser KK, Darras BT, Kang PB, Riley SO, Shriber E, Parad R, et al. Motor and cognitive assessment of infants and young boys with Duchenne muscular dystrophy: results from the Muscular Dystrophy Association DMD Clinical Research Network. Neuromuscul Disord. 2013;23(7):529-39.

42. Pane M, Mazzone ES, Sormani MP, Messina S, Vita GL, Fanelli L, Berardinelli A, Torrente Y, D'Amico A, Lanzillotta V, Viggiano E, D'Ambrosio P, Cavallaro F, Frosini S, Bello L, Bonfiglio S, Scalise R, De Sanctis R, Rolle E, Bianco F, Van der Haawue M, Magri F, Palermo C, Rossi F, Donati MA, Alfonsi C, Sacchini M, Arnoldi MT, Baranello G, Mongini T, et al. 6 Minute walk test in Duchenne MD patients with different mutations: 12 month changes. PLoS One. 2014;9(1):e83400.

43. Kota P, Aleksandrov AA, Riordan JR, Dokholyan NV. Dynamic coupling within NBD1 influences thermostability and function of CFTR. Pediatr Pulmonol. 2011:46:230.

44. Mah JK, Hu F, McDonald CM, Research Group C. Short stature prolonged ambulation in boys with Duchenne muscular dystrophy. Paper presented at the 47th Annual Congress of the Canadaian Neurological Sciences Federation; 5-8 Jun 2012; Ontario, Canada. Can J Neurol Sci. 2012;39 Suppl 3:S13.

45. Soderpalm AC, Magnusson P, Ahlander AC, Karlsson J, Kroksmark AK, Tulinius M, Swolin-Eide D. Bone mass development in patients with Duchenne and Becker muscular dystrophies: a 4-year clinical follow-up. Acta Paediatr. 2012;101(4):424-32.

46. Mazzone ES, Pane M, Sormani MP, Scalise R, Berardinelli A, Messina S, Torrente Y, D'Amico A, Doglio L, Viggiano E, D'Ambrosio P, Cavallaro F, Frosini S, Bello L, Bonfiglio S, De Sanctis R, Rolle E, Bianco F, Magri F, Rossi F, Vasco G, Vita G, Motta MC, Donati MA, Sacchini M, Mongini T, Pini A, Battini $R$, Pegoraro E, Previtali S, et al.: 24 month longitudinal data in ambulant boys with Duchenne muscular dystrophy. Erratum appears in PLoS One. 2013;8(11). doi:10.1371/annotation/cbe611fe-cda9-4d98-9574Oac18e109daa]. PLoS One. 2013;8(1):e52512.

47. Ricotti V, Manzur AY, Scott E, Muntoni F. Benefits and adverse effects of glucocorticoids in males with Duchenne muscular dystrophy: a UK perspective. Dev Med Child Neurol. 2012;54:14-5.

48. Fox DJ, Kumar A, West NA, DiRienzo AG, James KA, Oleszek J, Muscular Dystrophy Surveillance T, Research N. Trends with corticosteroid use in males with Duchenne muscular dystrophy born 1982-2001. J Child Neurol. 2015;30(1):21-6.

49. Pentek M, Baji P, Pogany G, Brodszky V, Boncz I, Gulacsi L. Health related quality of life of patients and their caregivers in rare diseases results of the BURQOL-RD project in Hungary. Value Health. 2014;17(7):A538.

50. Lim Y, Velozo C, Bendixen RM. The level of agreement between child selfreports and parent proxy-reports of health-related quality of life in boys with Duchenne muscular dystrophy. Qual Life Res. 2014;23(7):1945-52.

51. Bendixen RM, Lott DJ, Senesac C, Mathur S, Vandenborne K. Participation in daily life activities and its relationship to strength and functional measures in boys with Duchenne muscular dystrophy. Disabil Rehabil. 2014;36(22):1918-23.

52. Uzark K, King E, Cripe L, Spicer R, Sage J, Kinnett K, Wong B, Pratt J, Varni $J W$. Health-related quality of life in children and adolescents with Duchenne muscular dystrophy. Pediatrics. 2012;130(6):e1559-66.

53. Bendixen RM, Senesac C, Lott DJ, Vandenborne K. Participation and quality of life in children with Duchenne muscular dystrophy using the International Classification of Functioning, Disability, and Health. Health Qual Life Outcomes. 2012;10:43.

54. Pangalila RF, van den Bos GA, Bartels B, Bergen M, Stam HJ, Roebroeck ME. Prevalence of fatigue, pain, and affective disorders in adults with Duchenne muscular dystrophy and their associations with quality of life. Arch Phys Med Rehabil. 2015;96(7):1242-7.

55. Simon VA, Resende MB, Simon MA, Zanoteli E, Reed UC. Duchenne muscular dystrophy: quality of life among 95 patients evaluated using the Life Satisfaction Index for Adolescents. Arq Neuropsiquiatr. 2011;69(1):19-22.

56. Baiardini I, Minetti C, Bonifacino S, Porcu A, Klersy C, Petralia P, Balestracci S, Tarchino F, Parodi S, Canonica GW, Braido F. Quality of life in Duchenne muscular dystrophy: the subjective impact on children and parents. J Child Neurol. 2011;26(6):707-13.
57. Houwen-van Opstal SL, Jansen M, van Alfen N, de Groot IJ. Health-related quality of life and its relation to disease severity in boys with Duchenne muscular dystrophy: satisfied boys, worrying parents-a case-control study. J Child Neurol. 2014;29(11):1486-95.

58. Landfeldt E, Lindgren P, Bell CF, Schmitt C, Guglieri M, Straub V, Lochmuller $\mathrm{H}$, Bushby K. The burden of Duchenne muscular dystrophy: an international, cross-sectional study. Neurology. 2014;83(6):529-36.

59. Birnkrant DJ, Bushby KM, Amin RS, Bach JR, Benditt JO, Eagle M, Finder JD, Kalra MS, Kissel JT, Koumbourlis AC, Kravitz RM. The respiratory management of patients with Duchenne muscular dystrophy: a DMD care considerations working group specialty article. Pediatr Pulmonol. 2010;45(8):739-48.

60. McDonald CM, McDonald DA, Bagley A, Sienko Thomas S, Buckon CE, Henricson E, Nicorici A, Sussman MD. Relationship between clinical outcome measures and parent proxy reports of health-related quality of life in ambulatory children with Duchenne muscular dystrophy. J Child Neurol. 2010;25(9):1130-44.

61. Theadom A, Rodrigues M, Roxburgh R, Balalla S, Higgins C, Bhattacharjee R, Jones K, Krishnamurthi R, Feigin V. Prevalence of muscular dystrophies: a systematic literature review. Neuroepidemiology. 2014;43(3-4):259-68.

62. Mah JK, Korngut L, Dykeman J, Day L, Pringsheim T, Jette N. A systematic review and meta-analysis on the epidemiology of Duchenne and Becker muscular dystrophy. Neuromuscul Disord. 2014;24(6):482-91.

63. Angelis A, Tordrup D, Kanavos P. Socio-economic burden of rare diseases: a systematic review of cost of illness evidence. Health Policy. 2015;119(7):964-79.

64. TREAT-NMD Neuromuscular Network. Advancing diagnosis, care and treatment for those living with neuromuscular diseases around the world. 2015. accessed 9.10.15.

65. Bladen CL, Salgado D, Monges S, Foncuberta ME, Kekou K, Kosma K, Dawkins H, Lamont L, Roy AJ, Chamova T, Guergueltcheva V, Chan S, Korngut L, Campbell C, Dai Y, Wang J, Barisic N, Brabec P, Lahdetie J, Walter MC, Schreiber-Katz O, Karcagi V, Garami M, Viswanathan V, Bayat F, Buccella F, Kimura E, Koeks Z, van den Bergen JC, Rodrigues M, et al. The TREATNMD DMD Global Database: analysis of more than 7,000 Duchenne muscular dystrophy mutations. Hum Mutat. 2015;36(4):395-402.

66. Kempen JC, Harlaar J, van der Kooi AJ, de Groot IJ, van den Bergen JC, Niks $\mathrm{EH}$, Verschuuren JJ, Brehm MA. Reliability of the walking energy cost test and the six-minute walk test in boys with Duchenne muscular dystrophy. Neuromuscul Disord. 2014;24(3):216-21.

67. Lerario A, Bonfiglio S, Sormani M, Tettamanti A, Marktel S, Napolitano S, Previtali S, Scarlato M, Natali-Sora M, Mercuri E, Bresolin N, Mongini T, Comi G, Gatti R, Ciceri F, Cossu G, Torrente Y. Quantitative muscle strength assessment in Duchenne muscular dystrophy: longitudinal study and correlation with functional measures. BMC Neurol. 2012;12:91.

68. McDonald CM, Henricson EK, Abresch RT, Han JJ, Escolar DM, Florence JM, Duong T, Arrieta A, Clemens PR, Hoffman EP, Cnaan A, Cinrg I. The cooperative international neuromuscular research group Duchenne natural history study-a longitudinal investigation in the era of glucocorticoid therapy: design of protocol and the methods used. Muscle Nerve. 2013;48(1):32-54.

69. Roberto R, Fritz A, Hagar Y, Boice B, Skalsky A, Hwang H, Beckett L, McDonald C, Gupta M. The natural history of cardiac and pulmonary function decline in patients with Duchenne muscular dystrophy. Spine. 2011;36(15):E1009-17.

70. Sarrazin E, von der Hagen M, Schara U, von Au K, Kaindl AM. Growth and psychomotor development of patients with Duchenne muscular dystrophy. Europ J Paediatr Neurol. 2014;18(1):38-44.

71. Seferian AM, Moraux A, Annoussamy M, Canal A, Decostre V, Diebate O, Le Moing AG, Gidaro T, Deconinck N, Van Parys F, Vereecke W, Wittevrongel S, Mayer M, Maincent K, Desquerre I, Themar-Noel C, Cuisset JM, Tiffreau V, Denis S, Jousten V, Quijano-Roy S, Voit T, Hogrel JY, Servais L. Upper limb strength and function changes during a one-year follow-up in nonambulant patients with Duchenne muscular dystrophy: an observational multicenter trial. PLoS One. 2015;10(2):e0113999.

72. West NA, Yang ML, Weitzenkamp DA, Andrews J, Meaney FJ, Oleszek J, Miller $L A$, Matthews D, DiGuiseppi C. Patterns of growth in ambulatory males with Duchenne muscular dystrophy. J Pediatr. 2013;163(6):1759-1763.e1.

73. Pane M, Mazzone ES, Sivo S, Fanelli L, De Sanctis R, D'Amico A, Messina S, Battini R, Bianco F, Scutifero M, Petillo R, Frosini S, Scalise R, Vita GL, Bruno C, Pedemonte M, Mongini T, Pegoraro E, Brustia F, Gardani A, Berardinelli A, Lanzillotta V, Viggiano E, Cavallaro F, Sframeli M, Bello L, Barp A, Busato F, Bonfiglio S, Rolle E, et al. The 6 minute walk test and performance of upper limb in ambulant Duchenne muscular dystrophy boys. PLoS Curr. 2014;6. 
74. Mazzone E, Vasco G, Sormani MP, Torrente Y, Berardinelli A, Messina S, D’Amico A, Doglio L, Politano L, Cavallaro F, Frosini S, Bello L, Bonfiglio S, Zucchini E, De Sanctis R, Scutifero M, Bianco F, Rossi F, Motta MC, Sacco A, Donati MA, Mongini T, Pini A, Battini R, Pegoraro E, Pane M, Gasperini S, Previtali S, Napolitano S, Martinelli D, et al. Functional changes in Duchenne muscular dystrophy: a 12-month longitudinal cohort study. Neurology. 2011;77(3):250-6.

75. Henricson E, Abresch R, Han JJ, Nicorici A, Goude Keller E, Elfring G, Reha A, Barth J, McDonald CM. Percent-predicted 6-minute walk distance in Duchenne muscular dystrophy to account for maturational influences. PLoS Curr. 2012;4:RRN1297. https://www.ncbi.n/m.nih.gov/pmc/articles/ PMC3269886/

\section{Submit your next manuscript to BioMed Central} and we will help you at every step:

- We accept pre-submission inquiries

- Our selector tool helps you to find the most relevant journal

- We provide round the clock customer support

- Convenient online submission

- Thorough peer review

- Inclusion in PubMed and all major indexing services

- Maximum visibility for your research

Submit your manuscript at www.biomedcentral.com/submit 